\title{
Is Reallocation Related to the Cycle? A Look at Permanent and Temporary Job Flows
}

\author{
Andrew Figura* \\ Board of Governors of the Federal Reserve System
}

February 20, 2001

\begin{abstract}
How much of aggregate employment fluctuations is due to plants destroying and then recreating the same jobs over the cycle and how much is due to some plants permanently destroying jobs in a recession and other plants permanently creating jobs in an expansion? This paper decomposes plant level job flows into permanent and temporary components to answer this question, and finds that the permanent reallocation of jobs across plants accounts for approximately 30 percent of the cyclical fluctuations in aggregate employment.
\end{abstract}

"Mail Stop 80, Board of Governors of the Federal Reserve System, Washington, DC 20551. Email: jfigura@frb.gov. Research for this paper was conducted at the Center for Economic Studies. The views in this paper are those of the author and not necessarily those of the U.S. Census Bureau, the Federal Reserve Board, or its staff. I would like to thank John Shea, Judy Hellerstein, John Chao, Plutarchos Sakellaris, Bruce Fallick, Jason Cummins, Andy Levin, Darrel Cohen, Bill Wascher and Stephanie Aaronson. I would especially like to thank John Haltiwanger for supplying me with data, encouragement and much useful advice. 
The relationship between the reallocation of labor across production units and the business cycle has important implications for our understanding of the shocks that drive cyclical fluctuations, the amplification and propagation of shocks to the aggregate economy, and the correlation between labor input and labor productivity. ${ }^{1}$ Much of the debate on these issues has centered on whether permanent job destruction is concentrated in recessions. If it is, then the need to reallocate resources across production units could be responsible for some of the fluctuation in aggregate employment. ${ }^{2}$ This paper finds that this is, in fact, the case, with reallocation accounting for an important, but not predominant, share of aggregate employment fluctuations. In contrast to some previous estimates, this paper finds that reallocation across very broad industry groupings can account for all of total reallocation's contribution to aggregate employment movements. In addition, the joint behavior of reallocation's two componentspermanent job creation and permanent job destruction- indicates that reallocation is a time consuming and potentially very costly process.

As Abraham and Katz (1986) point out, empirically testing whether reallocation is concentrated in recessions can be problematic as researchers need to distinguish between temporary changes in production units' labor shares due to differing degrees of cyclical sensitivity across production units, on the one hand, and changes in labor shares due to the need to permanently relocate labor across production units, on the other.

Two broad strategies for distinguishing between these two effects have been used in the literature, both relying on measures related to permanence. First, researchers, such as Loungani, Rush, and Tave (1990) and Brainard and Cutler (1993) have tried to overcome the identification problem by using returns to capital (as measured by stock prices) in an industry to proxy for an industry's permanent demand for labor. ${ }^{3}$ Second, papers by Neumann and Topel (1991), Campbell and Kuttner (1996) and Loungani and Rogerson (1989) have tried to directly measure

\footnotetext{
${ }^{1}$ Research devoted to determining the relationship between reallocation and the cycle include Lilien (1982), Abraham and Katz (1986), Campbell and Kuttner (1996), Davis (1987), Brainard and Cutler (1993), Loungani, Rush, and Tave (1990), Murphy and Topel (1987), and Loungani and Rogerson (1989). Papers that investigate how reallocation can amplify and/or propagate aggregate shocks include Den Haan, Ramey and Watson (2000), Merz (1995) and Andolfatto (1996). Baily, Bartelsman and Haltiwanger (1998) decompose changes in labor productivity into a component due solely to changes within plants and a component due to reallocation of labor across plants and look at the cyclical behavior of both components. They find that reallocation related changes in productivity are counter-cyclical. Bar Levi (1998) looks at how incentives for workers to wait until recoveries to start looking for new jobs can impart a pro-cyclical bias to labor productivity.

${ }^{2}$ For more on theories behind the relationship between reallocation and the cycle, see Davis (1987).

${ }^{3}$ Brainard and Cutler (1993) use excess returns to capital, as defined by the Capital Asset Pricing Model.
} 
permanent, or long-lasting changes, in employment or unemployment, and have identified reallocation with the permanent changes. This paper follows in the second tradition and uses permanent employment movements to identify reallocation at the plant level.

To identify permanent employment movements I use a low pass filter. The low pass filter provides an intuitively simple identification criteria, but is, at the same time, based on a formal statistical model. It is applied as a symmetric moving average filter with weights derived from the frequency domain, and it emphasizes endurance or long-lasting changes as the main identifying criterion of permanence. Further, the identification is accomplished at the plant level rather than at the sectoral (Neumann and Topel, 1991, Campbell and Kuttner, 1996) or aggregate level (Davis and Haltiwanger, 1999). As reallocation is a plant-level phenomenon, this identification is both intuitively simpler and empirically clearer than identification schemes relying on more aggregate data. The filter requires a cut-off period, below which flows are considered temporary and above which flows are considered permanent. Previous research suggests that an 8 year cut-off period is appropriate to separate cyclical fluctuations from longer term movements. I emphasize the results from this cut-off, but also report results for a 5 year cut-off. In addition, I examine some ad hoc decomposition methods to both characterize the data and offer a point of comparison to some previous measures of permanent job flows.

I find that approximately $30 \%$ of job flows are reallocation related, i.e- related to longterm changes in employment. Permanent job destruction is concentrated around recessions, and, in particular, the recessions of the early 1980s, and accounts for about $30 \%$ of the increase in job destruction that occurs when employment growth is low. Permanent job creation is concentrated in expansions, and together permanent job flows account for nearly $30 \%$ of the change in aggregate employment occurring between periods of low and high employment growth. This result seems in accord with some of the previous literature, which assigns reallocation an important, but not predominant, role in the fluctuation of aggregate employment. In contrast to some of the existing literature, however, this paper shows that all of the cyclical change in aggregate employment caused by reallocation is due to reallocation across very broad (2 digit) industries.

The next section puts the paper in the context of the existing literature. Section two describes the data and considers a preliminary measure of the magnitude of permanent job flows. 
Section three introduces the main decomposition technique, the low pass filter, and presents results. In section four I perform some robustness checks. I consider whether the magnitude and cyclical concentration of permanent job flows are likely to differ for plants excluded from the main analysis and I provide a simple adjustment to correct for this potential bias. I also consider whether mismeasurement could bias my findings and look at how the permanent job flows I produce compare to persistent job flows measured by Haltiwanger and Schuh (1999). Section five looks at reallocation across industries, and section six concludes.

\section{Background}

This paper differs from previous papers about reallocation and the cycle by taking the establishment as the production unit of interest, by looking at two different components of reallocation (permanent job creation and permanent job destruction) and by using a statistical model to separate permanent and transitory components. Because of the differences between establishment data and the sectoral (Neumann and Topel, 1991) and worker (Loungani and Rogerson, 1989) data used by previous studies, interpretation of the results will be somewhat different. Compared to sectoral data, establishment level measures of reallocation should offer a more complete picture of the reallocation taking place in the economy. ${ }^{4}$ Compared to worker flows, measures of permanent job loss or job gain at establishments will be more removed from unemployment fluctuations because whether workers move into unemployment following job destruction or whether they move from unemployment as a result of job creation is not observed. On the other hand, establishment level long-term job creation and job destruction are more likely to reflect actual reallocation shocks, since these are presumed to affect a product or production process, not a firm/worker match and some of worker displacement can be due to match reasons rather than reallocation shocks to production processes.

Measurement of reallocation at the establishment level may also be closer to a more comprehensive measure of reallocation. To the extent that permanent job destruction represents a decline in demand for a plant's product, then the job loss entails not just the loss of establishment specific human capital (Jacobson, Lalonde and Sullivan, 1993) but also the loss of establishment or sector specific physical capital (Ramey and Shapiro, 1998) and organizational capital (Prescott and Visscher, 1980 and Atkeson and Kehoe, 2002). If this is true, then

\footnotetext{
${ }^{4}$ Davis and Haltiwanger (1992) argue that most reallocation is, in fact, within very narrowly defined sectors. Section 5 below also addresses this issue.
} 
measures of permanent job flows can be informative for models analyzing how the reallocation of plant specific capital, in addition to the reallocation of workers, can further amplify and propagate shocks to the economy (Den Haan, Ramey, and Watson, 2000). In addition, this paper measures not just reallocation, but also its two separate components- permanent job creation and permanent job destruction. Since the behavior of these two components provides information about the relative efficiency of reallocation (Caballero and Hammour, 1996) the measures presented in this paper should be more useful than previous ones.

Previous papers by Davis and Haltiwanger (1990, 1992) have also studied reallocation using the establishment as the production unit of interest. These papers define reallocation as the simultaneous creation and destruction of jobs (SUM) and find that it is negatively correlated with the cycle. But this measure is not without problems. On the one hand, it is uncertain whether SUM is, in fact, negatively related to the cycle once one accounts for trend growth (Foote, 1998). On the other hand, because asymmetric adjustment costs of employment or asymmetric aggregate shocks could also account for this correlation, ${ }^{5}$ it is uncertain whether the correlation actually measures the permanent reshuffling of resources across production units. Both criticisms would be addressed by a measure of permanent changes in employment at the establishment level.

Previous studies have used a variety of methods to distinguish permanent from transitory, none of which is without problems. Loungani and Rogerson (1989) use a simple persistence method criticized for its bias (Starr-McCluer, 1993). Neumann and Topel (1991) use a somewhat ad hoc method based on the correlation between current movements in sectoral shares and the amount of long-run (measured by a two sided moving average) movement in shares. Campbell and Kuttner (1996) use VARs and identify shocks causing permanent changes in manufacturing's share of employment as reallocation shocks. Unfortunately, the sensitivity of results to alternative identifying assumptions render VAR analysis problematic (Loungani, 1996,

\footnotetext{
${ }^{5}$ SUM being negatively correlated with net employment growth is equivalent to the variance of job destruction being greater than the variance of job creation, which is more intuitively associated with asymmetric adjustment costs (job destruction is less costly than job creation). To see the equivalence, note that $\operatorname{Corr}(\mathrm{Sum}, \mathrm{Net})=$ Corr $(\mathrm{Pos}+\mathrm{Neg}, \mathrm{Pos}-\mathrm{Neg})=\mathrm{E}\left[(\mathrm{Pos}+\mathrm{Neg}-\mathrm{E}(\mathrm{Pos}+\mathrm{Neg}))^{*}(\mathrm{Pos}-\mathrm{Neg}-\mathrm{E}(\mathrm{Pos}-\mathrm{Neg}))\right]=\mathrm{E}\left[\mathrm{Pos}^{2}\right]-\mathrm{E}\left[\mathrm{Neg}^{2}\right]-$ $(\mathrm{E}[\mathrm{Pos}])^{2}+(\mathrm{E}[\mathrm{Neg}])^{2}=\operatorname{Var}(\mathrm{Pos})-\operatorname{Var}(\mathrm{Neg})$, where Pos represents job creation and Neg represents job destruction. On asymmetric adjustment costs and cyclical variation in dispersion measures, see Weiss (1989).
} 
and Faust and Leeper, 1997). Similar to Loungani and Rogerson (1989) and Neumann and Topel (1991) I use the endurance of employment changes to identify reallocation related movements in employment. In contrast to both of these studies, I use a statistical model to distinguish high frequency from low frequency changes and analyze how results change when the cut-off frequency between low frequency (permanent) and high frequency (transitory) is altered.

\section{The Data, Permanent Job Flows and Some Ad Hoc Decompositions}

\subsection{Data}

This paper uses plant level employment data from the Census Bureau's Longitudinal Record Data set, or LRD. The LRD derives from data collected every 5 years by the Census of Manufacturers (CM) and data collected annually by the Annual Survey of Manufacturers (ASM). ${ }^{6}$ While the CM collects data for the universe of manufacturing plants, the ASM is a sample survey of approximately 50,000 to 70,000 plants drawn from the CM. Plants selected to be in the ASM remain in it for 5 years, allowing researchers to follow plants' employment histories across time. Some employers are included in consecutive ASM panels, enabling researchers to track their employment over longer periods of time. For more information on the construction of job flows from the LRD, see Davis, Haltiwanger and Schuh (1996), henceforth DHS.

\subsection{Defining Job Flows}

Job flows are defined as in DHS. A decrease in employment for a plant from period $t$ - 1 to $t$ is defined as a negative job flow, while an increase is defined as a positive job flow. Aggregate job creation is defined as the sum over all plants of positive employment changes, and aggregate job destruction is defined as the absolute value of the sum of negative employment changes. ${ }^{7}$ To compute aggregate job flow rates for period $t$, DHS divide aggregate job creation and aggregate job destruction by the average of aggregate employment in periods $t$ and $t-1$. Flows derived from job creation and job destruction rates are SUM, the sum of job creation and job destruction, and NET, the difference between job creation and job destruction.

\footnotetext{
${ }^{6}$ Although the ASM is an annual survey, it collects production worker employment data for four different months during the year, making possible the computation of quarterly job flows.

${ }^{7}$ Because a job flow is measured as the net change in an establishment's employment from time $t$ - 1 to $t$, it does not include flows from plants destroying one type of job and creating a different type of job between $t-1$ and $t$.
} 
This paper seeks to decompose plant level job flows into permanent and transitory components. Call plant $i$ 's employment change or job flow from period $t-l$ to period $t j f_{i, t}$. I will seek to decompose this into a permanent component, $j f p_{i, t}$, and a temporary component, $j f t_{i, t}$. If $j f p_{i, t}$ is negative, then it is called permanent job destruction, and if it is positive, it is called permanent job creation. One can then sum over plants' levels of permanent job flows to arrive at aggregate permanent job creation and aggregate permanent job destruction. Division of these sums by an average of aggregate employment in $t$ and $t-1$ yields permanent job flow rates. Job flows produced by the need to permanently reallocate jobs across plants are identified as aggregate permanent job flows. The magnitude and cyclical concentration of permanent flows will reveal how important reallocation related job flows are to cyclical changes in aggregate employment.

\subsection{Permanent Job Flows}

The distinction between permanent and temporary job flows in this paper is very different from the distinction between permanent and temporary worker flows. The latter concept distinguishes between layoffs that end when workers are recalled back to the same job and layoffs that result in workers finding new jobs. In contrast, permanent and temporary job flows distinguish between changes in the underlying permanent or normal level of employment at a plant, and changes in employment around that normal or permanent level, which do not result in lasting or enduring changes in the plant's employment. Permanent job flows would be associated with changes in the plant's scale or alterations in its relative factor demands. Temporary job flows would be associated with changes in the utilization of a fixed production process that occur with temporary changes in demand.

One can think of a plant being affected by two types of shocks: aggregate shocks related to business cycles and relative taste/technology shocks related to the relative demand for the good(s) produced by a plant compared to goods produced elsewhere. The former type of shock is stationary and of limited duration; the affect of the shock on a plant's level of employment does not last very long. The second type of shock is non-stationary and there is no tendency for it to disappear with time. Thus, in looking at plant level employment movements, as the period of time increases, the magnitude of net employment changes, or job flows, due to cyclical or aggregate shocks decreases while the magnitude of job flows due to relative technology shocks 
(hereon the term technology shock includes both changes to the relative demand for a plant's products, taste shocks, and changes to the plant's production technology) decreases much more slowly, if at all. A cut-off period associated with the maximum duration of aggregate demand shocks should remove fluctuations in employment due directly to changes in aggregate conditions, while preserving the large majority of job flows due to relative technology changes. This follows from the assumption that relatively few plants will undergo two changes in relative technology, that result in opposite effects on labor demand within a period of time typically associated with the duration of a business cycle.

The effect of reallocation on aggregate employment fluctuations is determined by both the magnitude and cyclical concentration of reallocation. If there were no costs associated with reallocation, then permanent job flows would occur whenever relative technology shocks arrived, and if these shocks were not correlated with the cycle, then neither would permanent job flows be. But the presence of costs associated with changes in the production process could cause permanent job flows to become correlated with the cycle though shocks determining the relative demand for a plant's product are not. Specifically, if aggregate shocks affect the benefits of permanently altering a plant's production process and its demand for labor (as reflected in the discounted stream of returns to such a change), differently than they do the costs of restructuring (acquiring or writing down assets) then permanent changes should be correlated with the cycle, as plants on the margin between restructuring or not restructuring are pushed in one direction or the other. ${ }^{8}$ Such a correlation would result from reallocation timing rather than reallocation shocks.

Lilien (1982) originally attributed the correlation between reallocation and the cycle to the occurrence of reallocation shocks. Since then, most models of reallocation have attributed the correlation to reallocation timing effects. In this case, the correlation contains no information about the origins of economic fluctuations, but does contain information about their costs. If a recession occurs with no permanent job destruction, then costs, in terms of scrapped old investments and required new investments, are relatively minor. If, on the other hand, considerable permanent job destruction occurs, then costs are higher. The two kinds of

\footnotetext{
${ }^{8}$ In Mortensen and Pissarides (1994), because a downturn causes the cost of relocating workers from less to more productive job sites to decrease by more than the discounted stream of benefits of relocation, permanent job destruction is concentrated in downturns.
} 
employment fluctuations, one occurring through reallocation, the other through changing utilization, would also require different public policy responses (Ramey and Watson, 1997, and Caballero and Hammour, 1996).

\subsection{A Preliminary Measure of the Magnitude of Permanent Job Flows}

A decomposition of job flows into permanent and temporary components supposes that plants have both permanent and temporary job flows. Evidence on quarterly and annual job flows from DHS supports this notion. Annual job flow rates average close to $10 \%$ for both job creation and job destruction, while quarterly job flows are a little over 5\%. If quarterly flows were never reversed, then annual flows would measure close to $20 \%$ instead of $10 \%$. $^{9}$ Instead, around half of quarterly job flows are reversed within the year.

Comparing job flows at different frequencies is one simple method to estimate the importance of permanent job flows. In addition to quarterly and annual job flow measures, one can compute job flows at frequencies of 2, 3 and 4 years within each ASM panel. Aggregate job creation at a 3 year frequency, for example, would just be the sum over plants whose employment at period $t+3, e_{t+3}$, minus employment at period $t, e_{t}$, is positive. More generally, job creation and job destruction at frequency $i$ are

$$
\begin{aligned}
& J C_{i, t}=\sum_{e_{j, t+i}-e_{j, t}>0}\left|e_{j, t+i}-e_{j, t}\right| \\
& J D_{i, t}=\sum_{e_{j, t+i}-e_{j, t}<0}\left|e_{j, t+i}-e_{j, t}\right|
\end{aligned}
$$

where $j$ indexes the plant and $i$ indexes the frequency of the flow. To change these measures into rates, I divide by the average of employment across the five years of the panel. Table 1 reports aggregate job flow rates at these different frequencies, as well as the implied rate if annual job flows were never reversed (Cumulative Flows). Job flows at frequency $i$ are computed as employment at period $(4 * i)+1$ of the 20 period panel minus employment in period 1 for all plants

\footnotetext{
${ }^{9}$ This is not exactly the case because annual job flows include production as well as non-production workers, while quarterly job flows only include production workers. Since plants change production worker employment more readily than they change non-production worker employment, annual production worker rates are somewhat higher than rates for production and non-production workers.
} 
with non-missing employment for all 20 periods of each ASM panel (e.g. job flows at a two year frequency in the 1974-78 panel are computed from the difference in employment levels in 1976:1 and 1974:1). The average 4 year frequency SUM rate is reported in panel E as $32.32 \%$. This is the average sum of net job creation and net job destruction over the four years of the panel. The average cumulative 4 year SUM rate is $63.66 \%$. This is the average sum of gross annual job creation and gross annual job destruction over the same four years. From these figures it appears that about half of annual job flows do not contribute to changes in plants' employment over a four year horizon.

Figure 1 provides a picture of some of the same information. The $\mathrm{Y}$ axis measures average job flow rates over the 4 ASM panels. The three panels show cumulative job flow rates (dashed lines) and job flow rates at different frequencies (solid lines) for Creation, Destruction and SUM. From 0 to 1 the frequency measure and cumulative measure have the same slope, but after period 1 the cumulative measures increase at approximately the same rate, while the frequency measures level off significantly because many of the job flows from the previous year are reversed. Thus, job flows at lower frequencies filter out higher frequency employment changes.

The slope of the frequency measure provides a rough estimate of a long-run rate of reallocation. The difference $\mathrm{e}_{\mathrm{j}, t+\mathrm{i}}-\mathrm{e}_{\mathrm{j}, \mathrm{t}}$ measures the net accumulation of employment changes from $t$ to $t+i$ for plant $j$. From $t+i$ to $t+i+1$ some plants will add to this employment difference, $\left|e_{j, t+i+1}-e_{j, t}\right|>\left|e_{j, t+i}-e_{j, t}\right|$, while some plants will subtract from it, $\left|e_{j, t+i}-e_{j, t}\right|>\left|e_{j, t+i+1}-e_{j, t}\right|$. The change in the numerator of the slope of the SUM frequency measure is the sum of these two types of employment changes. In the first period, all plants' job flows add to the slope of the SUM frequency measure because no previous employment movements are reversed. But in the $2^{\text {nd }}$ through $4^{\text {th }}$ periods there are both additions and subtractions. Over time, long-run changes in plants' employment levels accumulate, and these changes cause the SUM curve to rise, as plants drift away from previous employment levels, see figure 1. In any given year, cyclical factors and other factors peculiar to a panel may cause the slopes of the job creation and job destruction frequency curves to turn up (down) and then down (up) as short-term job creation and job destruction increases and then decreases. If one averages over job creation and job destruction by looking at SUM and further averages over different phases of the cycle by looking at the 
average movement of SUM over the 4 panels, these factors are mitigated, and after the first period there appears to be a constant change in the SUM frequency measure, or a constant movement of plants away from previous employment levels.

I compute an average long-term rate of reallocation as the slope from the $4^{\text {th }}$ to the $1^{\text {st }}$ periods of the SUM frequency graph. Using this method, the average annual permanent rate of reallocation shown in panel $\mathrm{E}$ of table 1 is $5.08 \%$, or about $30 \%$ of total annual flows and about $15 \%$ of quarterly flows. ${ }^{10,11}$ Figure 1 also breaks down the long-term changes in SUM into longterm job creation and long-term job destruction. Given the downward trend in manufacturing employment, the long-run changes in employment levels due to permanent job destruction are greater than long-run employment changes due to permanent job creation.

Though the frequency measure allows one to estimate the average magnitude of a permanent component, it does not allow a very precise estimate of whether the permanent component is cyclically correlated. To do this, one must decompose job flows in each period into permanent and temporary components and define a measure of the cycle. A common measure of the cycle is the time series of recession indicators published by the NBER. One method of looking at the cyclical concentration of job flows computes differences in means between recessions and expansions. In recessions, both a decline in job creation and an increase in job destruction cause aggregate employment to decline. Part of the changes in aggregate job creation and job destruction is due to changes in permanent job creation and permanent job destruction and this part defines the share of the change in aggregate employment due to permanent job flows. However, employment may exhibit cyclical movements that are not well captured by simply distinguishing between recessions and expansions. Employment movements in manufacturing may lead or lag the cycle, for example. Also, in an economy with trend growth, a cyclical downturn may occur without entering into a recession. To address these concerns, I identify periods when the 4 quarter growth in employment is below and above its

\footnotetext{
${ }^{10}$ Dunne, Roberts and Samuelson (1989) report implied average annual SUM rates from 5 year job flows from the complete CM of $11.7 \%$ (58.5\% over five years). This measure does not, however, control for the effect of short term job flows. A rough adjustment, that is similar to the above calculations of a permanent long-run rate of reallocation, assumes that the average absolute change in employment levels after the first period represents long-run reallocation. I assume that in the first period job flows are equal to annual averages reported in DHS. The average annual SUM rate is $19.4 \%$. 58.5 minus 19.4 divided by 4 is approximately 9.8 percent. The Dunne, Roberts, Samuelson measure also includes births and deaths, which are not accounted for in the ASM balanced panels.

${ }^{11} \mathrm{~A}$ more conservative measure takes the average slope from the $2^{\text {nd }}$ to the $4^{\text {th }}$ periods and is $4.55 \%$.
} 
mean and present differences in mean flows over this indicator, as well as differences across recessions and expansions.

\section{The Cyclical Concentration of Permanent Job Flows}

\subsection{The Baxter and King Low Pass Filter}

The low pass filter derived by Baxter and King (1999) has the advantage that it can be implemented as a symmetric backward and forward moving average filter, even though it is theoretically motivated by the imposition of restrictions in the frequency domain. ${ }^{12}$ Thus, it is straight forward and easy to apply, but at the same time derived from a statistical model with easy to interpret assumptions. The derivation of the filter begins with the spectral representation theorem, which states that any stationary time series can be described by the sum of an infinite number of orthogonal cyclical series of different frequencies (see Priestly, 1981).

$$
y_{t}=\int_{-\pi}^{\pi} \xi(\omega) d \omega
$$

After applying a linear filter to a series, its spectral representation is

$$
\begin{aligned}
& y_{t}^{*}=a(L) y_{t}=\int_{-\pi}^{\pi} \alpha(\omega) \xi(\omega) d \omega \\
& \alpha(\omega)=\sum_{h=-K}^{K} a_{h} e^{i w h}
\end{aligned}
$$

$\alpha(\omega)$ is the frequency response function of the linear filter $\quad a(L)=\sum_{-K}^{K} a_{h} L^{h} \quad$, where $\mathrm{L}$ is the lag operator. ${ }^{13}$ Thus, the series $y_{t}{ }^{*}$ is a weighted sum of cyclical series of different frequencies.

\footnotetext{
${ }^{12}$ Christiano and Fitzgerald (1999) develop a band pass filter, that uses all of the data available for a series, instead of the fixed window used by the Baxter and King filter. The disadvantages of the Christiano and Fitzgerald filter are that it is non-symmetric, and thus induces phase shift, and it is non-stationary. The first draw back may introduce some bias in measures of the cyclical concentration of permanent job flows and the second draw back may make it problematic to compare permanent job flows across time and perhaps across plants with different length time series. Consequently, I use the Baxter and King filter, which is a restricted form of the Christiano and Fitzgerald filter. ${ }^{13}$ This follows from the fact that convolution in the time domain is equivalent to multiplication in the frequency domain.
} 
The object of a low-pass filter is to place zero weight on frequencies above a specified cut-off. To pick out employment changes related to permanent movements in a plant's employment, a filter should assign positive weights to only very low frequencies. These are the changes in employment that are the most enduring or long-lasting. Once the appropriate frequencies are zeroed out, the revised series can be translated back into the time domain according to

$$
\begin{aligned}
& y_{t}^{p}=a^{p}(L) y_{t} \\
& a^{p}(L)=\sum_{h=-K}^{K} a_{h}^{p} L^{h} \\
& a_{h}^{p}=\frac{1}{2 \pi} \int_{-\pi}^{\pi} \alpha^{p}(\omega) e^{i \omega h} d \omega \\
& \alpha^{p}(\omega)=1 \text { if }|\omega| \leq \bar{\omega} \\
& \alpha^{p}(\omega)=0 \text { if }|\omega|>\bar{\omega}
\end{aligned}
$$

$\bar{\omega}$ is the cut-off frequency, i.e.- the frequency below which employment movements are considered permanent, and $y^{p}$ is permanent, or very low frequency, movements in the series $y$. The moving average coefficients used to filter out high frequency components, $a_{h}^{p}$, are derived from the frequency domain as the inverse Fourier transform of the frequency response function. The optimal linear filter would be a two way infinite lead/lag polynomial. While the data do not allow the application of such a filter, an accurate decomposition requires leads/lags of sufficient length. At the same time, the longer the filter the fewer the observations contained in the component series. Thus, there is a tension between desiring an accurate decomposition on the one hand and as many data points as possible, on the other. Baxter and King (1999) use simulations to examine this trade-off and recommend using 12 quarters of data backwards and forwards to construct a filter that isolates business cycle frequencies.

\subsection{Measuring Permanent Job Flows}

To construct aggregate permanent job flow series, I first create 16 overlapping 7 year panels from 1972-1993. Thus, for example, the first panel would cover the years 1972-1978, the second 1973-1979, etc. For each plant in each panel, I use a low-pass filter, based on a weighted average of employment in the current quarter, 11 quarters forward, and 11 quarters backward, with weights derived from the frequency domain as described above, to decompose employment 
changes for the middle year in each panel into permanent and temporary components. ${ }^{14}$ Thus, for the first panel I can construct permanent and temporary job flows for each plant for the four quarters of $1975 .^{15}$

To see how plants represented in the overlapping 7 year panels may differ from plants in the entire ASM sample, table 2 compares the properties of overall job flows computed from the overlapping 7 year panels with the properties of time series of job flows reported by DHS. Though plants in the overlapping panels account for $30-45 \%$ of the plants in the typical ASM panel, they represent about two thirds of ASM employment and about half of total manufacturing employment. For the most part, the cyclical behavior of job flows from the two samples is quite similar. ${ }^{16}$

Baxter and King rely on Burns and Mitchell (1946) in choosing 8 years as the frequency cut-off for cyclical movements. A larger cut-off means a more conservative estimate of permanent flows. Because time series of aggregate job flows suggest fluctuations in job flows are concentrated in the 3 to 4 year period surrounding recessions and recoveries, I also look at results from a 5 year cut-off filter.

Table 3 and figure 2 present results for the manufacturing sector for an 8 year cut-off. Permanent job flows account for a significant, but not predominant, share of total job flows, $15 \%$ of job creation and $21 \%$ of job destruction, respectively. These percentages are quite similar to estimates of long-term reallocation from the job flow frequency measures presented in section 2. Permanent job flows are cyclically related with permanent job destruction concentrated in periods of employment contraction and permanent job creation concentrated in periods of

\footnotetext{
${ }^{14}$ I use an 11 quarter instead of a 12 quarter filter because the construction of job flows requires a difference operation on decomposed employment. Thus, with 7 years of data a 12 quarter filter would not allow the construction of job flows for the first quarter of the middle year. The 11 quarter filter allows one to estimate employment decompositions for the 6 middle quarters of each panel. This means that each panel has permanent job flows for the first quarter of its middle year and the first quarter of the next panel's middle year. To smooth the aggregate series, I take the average of the first quarter estimate from consecutive panels.

${ }^{15}$ While the 7 year filter in most years requires the use of data from two consecutive ASMs, in some years, the middle year of each ASM panel, it requires the use of data from three consecutive ASM panels. Thus, in constructing aggregate time series of permanent flows, one must be aware that in some years (the middle year of each panel) the sample of plants is smaller and somewhat different than in others.

${ }^{16}$ The means of job creation and job destruction are lower for the overlapping panels. Given the negative correlation between plant size and the magnitude of job flows, this was to be expected. The standard deviations of job creation are similar for both series, while the standard deviation of job destruction is lower for the overlapping panels. Correlations between the same series across panels are quite high: around .95 for NET and Job Destruction, and around .8 for Job Creation and SUM.
} 
employment growth. Permanent job destruction accounts for $14 \%$ of the cyclical change in job destruction (using the above and below average employment growth indicator as a measure of the cycle), and permanent job flows account for about $15 \%$ of the change in employment over the cycle, as shown by permanent NET's share of the difference in total NET in above and below average growth periods. Results from the recession/expansion indicator show a smaller contribution to aggregate employment fluctuations. Because the low pass filter acts to smooth permanent job flows, changes in these flows are spread out rather than concentrated. Since the below average employment growth indicator is a more diffuse (includes more quarters) indicator of sub-par employment growth than the recession indicator, it is better able to capture the contribution of permanent job flows to changes in employment.

To the extent that one believes permanent changes to be one-time discrete events, smoothness is a disadvantage. For example, if a plant's actual job flows over 45 periods are 0 for the first 22 periods, -100 in the $23^{\text {rd }}$ period and 0 for the remaining 22 periods, the low pass filter would estimate permanent job flows for the middle 23 periods to be $\{-2,-3,-3,-4,-4,-5,-$ $5,-5,-6,-6,-6,-6,-6,-6,-6,-5,-5,-5,-4,-4,-3,-3,-2\} .{ }^{17}$ The one time change is spread out over many periods. As a result, the low pass filter estimates may understate the cyclical concentration of permanent job flows. A cursory examination of actual plant-level job flows reveals both gradual and abrupt lasting-changes in employment to be important; but abrupt changes are often associated with births and deaths (which I account for below). Therefore, the properties imparted to permanent employment movements by the low pass filter do not appear unrealistic. $^{18}$

\footnotetext{
${ }^{17} \mathrm{~A}$ by-product of smoothing can be implicit within plant job flows in opposite directions in the same period. In the above example in all periods except the $23^{\text {rd }}$, there occurs within plant permanent job destruction and within plant temporary job creation to counter balance the permanent job destruction and keep the net change in employment caused by permanent and temporary job flows at time $t$ to equal the total change in employment at time $t$. For the low pass filter with an 8 year cut-off, I measure the sum of permanent and temporary job flows in excess of total job flows to be about $50 \%$ of permanent job flows, indicating that the low pass filter causes permanent job creation (destruction) to occur in many instances when total job creation (destruction) does not. Permanent job destruction in excess of total job destruction tends to rise before recessions and fall off in expansions, indicating that permanent job destruction may be more concentrated than estimated by the low pass filter. Permanent job creation in excess of total job creation does not vary as much, indicating that any underestimation of the cyclical concentration of permanent job creation would not be as large.

${ }^{18}$ An alternative statistical model that emphasizes both enduring and abrupt changes is a model of regime switching with an absorbing state. But this model would be appropriate only if there were a single discrete permanent change in employment for a plant over a period of time. Also, the non-linear estimation required would make it inappropriate for panels of 20,000 plants. An alternative statistical model that also emphasizes a smoother permanent component would be an unobserved components model with a permanent component parameterized as a
} 
Table 3 and figure 2 also show results for a 5 year cut-off. The main difference with the 8 year cut-off resides in the recession and expansion of 1974-1979. The 5 year cut-off shows relatively large permanent job creation and job destruction for this period, while the 8 year cutoff does not. Apparently, there was a fair amount of medium (5-8 year period) term job flows, as plants destroyed jobs in the 1974-75 recession, but created them again relatively late in the ensuing expansion. Also, although the 5 year cut-off exhibits significant increases in permanent job destruction in the 1985-86 slowdown, the 8 year cut-off does not.

The added job flows picked up by the 5 year cut-off are within plant flows-i.e. the same plant that destroys jobs in a recession creates them in a recovery. While these could be permanent within plant job flows, they occur within a period of time less than the upper range of a typical business cycle duration. If they are permanent job flows, then the plants would have first permanently destroyed one production process and its underlying organizational and physical capital and then created a different one in a period of 5 to 8 years. If they are temporary job flows then some plants take over 5 years and up to 8 years to fully recover from any employment changes caused by an aggregate (or some other temporary) shock. Different assumptions about these job flows lead to quite different conclusions about the importance of reallocation to aggregate employment fluctuations. Under the assumption that 5-8 year job flows are cyclical, reallocation (due to continuers, i.e. not including births and deaths) accounts for about $15 \%$ (13\% using NBER recession dates) of the change in aggregate employment over the course of a cycle. Under the assumption that 5-8 year job flows are permanent, reallocation accounts for over $40 \%$ (24\% using NBER recession dates) of the change in aggregate employment. Because drawn out adjustment to aggregate shocks seems more likely than back to back restructuring or rescaling events that lead to opposite movements in employment over a relatively short time-span, I emphasize results from the 8 year cut-off.

The above measure of permanence considers only job flows from continuing plants. Other likely sources of permanent job flows are the shutting down and starting up of plants. The start-up of a plant requires a sunk investment in physical and organizational capital. If the new plant proves unsuccessful, these investments are not easily transferred to alternative uses.

random walk with stochastic drift (Harvey, 1993). But parameter estimates from this model are often in practice not very precise. Parameters that assign all of a plant's movements to the permanent component and parameters that assign all movements to the temporary component are often very close to being equally likely. 
Similarly, the death of a plant forces the plant to forego the option value of producing output at the plant in more favorable circumstances, without recreating itself. If the likelihood of circumstances improving are large, then it is unlikely the plant will forego this option by shutting-down. If a plant must commit to an action, whose costs are not easily recoverable, then the plant will only do so if it believes that the circumstances underlying the decision are not likely to change. Thus, both the birth and death of a plant are likely associated with a large amount of permanence.

Thanks to work by DHS, data on births and deaths in the manufacturing sector are readily available. ${ }^{19}$ Table 4 shows statistics on births and deaths and figure 3 graphs time series. ${ }^{20}$ Comparing the cyclical concentration of births and deaths to the behavior of permanent job flows for continuing plants, one finds them to be similar. Deaths are concentrated in below average growth periods, while births are concentrated in above average growth periods.

To compute a series of permanent job flows that includes both permanent flows from continuing plants and births and deaths, I add a continuing plant permanent job flow rate to a birth and death rate. Before adding the two sets of job flows, the continuers' rate must be multiplied by continuing plants' share of employment. ${ }^{21}$ Statistics on these combined rates are reported in table 5. Figure 4 graphs time series. Using the 8 year cut-off, permanent job flows now account for $29 \%$ of total job flows. Job destruction accounts for $27 \%$ of the increase in job destruction in low growth periods, and permanent flows account for $28 \%$ of the change in net employment growth over the cycle.

\footnotetext{
${ }^{19}$ For measures of births and deaths outside the manufacturing sector see Spletzer (2000).

${ }^{20}$ These series are taken from John Haltiwanger's website: www.bsos.umd.edu/econ/haltiwanger/download.htm.

${ }^{21}$ The continuing plants' fraction of employment is just 1 minus the birth and death fraction of employment, which given the DHS definition of employment is just one-half times the sum of the birth and death rates reported by DHS. The fraction of birth and death employment is
}

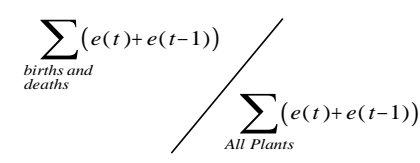

The birth and death job flow rate reported by DHS is

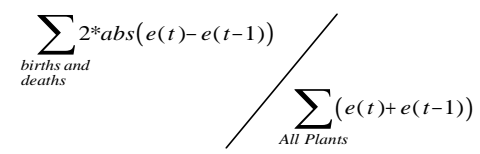

with $e(t)=0$ for deaths and $e(t-1)=0$ for births. 
Overall, the above evidence offers some support to theories which predict that reallocation should be concentrated in recessions. The support is tempered by two considerations. First, although permanent job destruction is concentrated in recessions, permanent job creation is not, and permanent SUM is only weakly countercyclical. Reallocation activity does not manifest itself as the simultaneous destruction and creation of jobs. Instead, first jobs are destroyed, and then only gradually are jobs created. The implications are that reallocation is a time consuming and potentially very costly process, and theories of reallocation must incorporate significant frictions in the movement of resources from one production site to another to prevent reallocation from being synchronized. Second, though the share of aggregate employment changes attributed to reallocation is significant, the larger share belongs to job flows that are temporary. One must also bear in mind that while the above analysis supports models that predict that reallocation is concentrated cyclically, it does not distinguish between these models. Both theories which state that shocks to reallocation coincide with the cycle (Lilien, 1982), and theories which state that reallocation shocks are not correlated with the cycle, but that reallocation decisions are (Mortensen and Pissarides, 1994), are consistent with the above analysis.

\section{Robustness}

\subsection{Small Plants}

The decomposition results in section 3 relied on the existence of a long (7 year) continuous time series of employment for a plant. Because the ASM panel is renewed every 5 years and the ASM is a sample survey, with probability weights inversely proportional to size, it is mostly large plants that have long enough time series to perform the decompositions. One might then wonder whether the unrepresentative nature of the decompositions biases the aggregate statistics produced by them. To investigate this possibility, I look, to the extent possible, at how the cyclical concentration and magnitude of permanent job flows at small plants might be different from larger plants.

As noted by DHS, small plants have higher rates of job creation and job destruction than larger plants. Of interest in this paper is how big a share of these larger flows are permanent, and whether these permanent flows are cyclically related. While the plants in the 7 year panels are disproportionately larger plants, small plants are also present. I separate plants in the panels 
into three roughly equal size categories: fewer than 100, between 100 and 250, and greater than 250 average employment for the seven year panel, and see whether long-term job flows behave differently over the cycle for the three groups. Each group has an average of about 8,000 plants in each panel. Figure 5 shows time series of permanent job flows for the different sized plants. The magnitude and the cyclical concentration of permanent job flows is very similar for all three size groups. Job creation appears slightly more pro-cyclical for smaller plants, while job destruction appears slightly more counter-cyclical for larger plants.

If the permanent job flows of small and medium plants excluded from the seven year panels are in amount and cyclical concentration similar to plants included in the panels, then new bias adjusted estimates of permanent job flows would sum job flows of small, medium, and large plants weighted by their share in aggregate employment, as opposed to their share of each panel's employment.

$$
\begin{aligned}
& p j f_{t}=p j f_{t}^{\text {small }} * \text { eshare }_{t}^{\text {small }}+p j f_{t}^{\text {medium }} \text { eshare }_{t}^{\text {medium }}+p j f_{t}^{l \text { arge } e} \text { eshare }_{t}^{l \text { arge }} \\
& \text { eshare }_{t}^{i}=\frac{e_{t}^{i}}{e_{t}}, i=\text { small,medium, large }
\end{aligned}
$$

where $e_{t}$ is aggregate employment and $e_{t}^{i}$ is total employment for establishments in size category $i$. Table 6 and figure 6 shows permanent job flows following this bias correction. The results are very similar to the previous estimates. Now permanent job flows account for 30 percent of total job flows and 29 percent of the change in aggregate employment over the cycle.

\subsection{Potential Bias Arising from Leakage}

The estimates of permanent job flows come from panels of about 20,000 plants, rendering any test of the correlation between permanent job flows and the cycle highly significant. But one could still question whether the error in measuring plant-level permanent job flows is somehow correlated with the cycle and biasing the results. Because permanent job flows are derived from an approximate low-pass filter, some "leakage" of high frequency employment movements into permanent job flows does occur. Figure 7 shows the frequency weights for an 11 quarter forward and backward low pass filter with an 8 year cut-off along with the weights of an ideal filter. The weights for frequencies greater than the cut-off are close to, 
but not exactly equal to, zero. If low frequency job flows are unrelated to the cycle, but high frequency job flows are, then leakage of high frequency flows into estimated low frequency flows could bias estimates toward finding a cyclical relationship.

To see whether this occurs, I construct a measure of "leakage" as the amount of higher frequency fluctuations included in permanent job flows. If over a short time span a plant has both permanent job creation and permanent job destruction, then some higher frequency employment fluctuations are included in permanent job flows. To estimate the extent that this occurs, I link plants across eleven consecutive years. I can construct permanent job flows for each plant for the five middle years of the eleven year panel. As a measure of high frequency movements in permanent job flows, I compute 1 minus the ratio of net within plant permanent job flows over the five year period to gross permanent job flows over the same period. If a plant only has permanent job creation or only has permanent job destruction over the five year period, then net within plant permanent job flows equals gross permanent job flows, and the ratio equals 1-1=0. No high frequency movements are included in permanent job flows and no leakage occurs. If, on the other extreme, permanent job creation equals permanent job destruction over the five year period, then net permanent job flows are 0 and the ratio equals $1.100 \%$ of permanent job flows are due to leakage. ${ }^{22}$ From 1975 to 1990 , I estimate leakage to be about 20\%; more importantly, however, leakage as a percent of permanent job flows does not vary significantly over the cycle. Though there are some higher frequency fluctuations included in permanent job flows, these fluctuations are of limited magnitude and do not cause permanent job flows to change over the cycle. Thus, the relationship between the cycle and permanent job flows does not appear to be due to leakage.

\subsection{Persistent Job Flows}

Persistent job flow measures from DHS were a first attempt to measure quarterly permanent job flows. Because persistence rates have been used by some researchers, it would be of interest to compare their behavior with the permanent job flows estimated in section 3. A

\footnotetext{
${ }^{22}$ Some of what I measure as leakage occurs as a plant smoothly creates (destroys) and then destroys (creates) jobs over a period greater than, but close to, 8 years in length. In this case, part of the relatively high frequency changes in employment that I measure would not be caused by imprecise filtering, but, instead, by the presence of job flows with periods close to 8 years. The leakage analysis I perform could also be viewed then as a test of how much my results depend on flows with periods close to 8 years.
} 
persistent job flow is that part of a job flow that endures into the future or is not reversed over some specified future horizon. DHS define a $\mathrm{T}$ period persistence rate at time $\mathrm{t}$ as

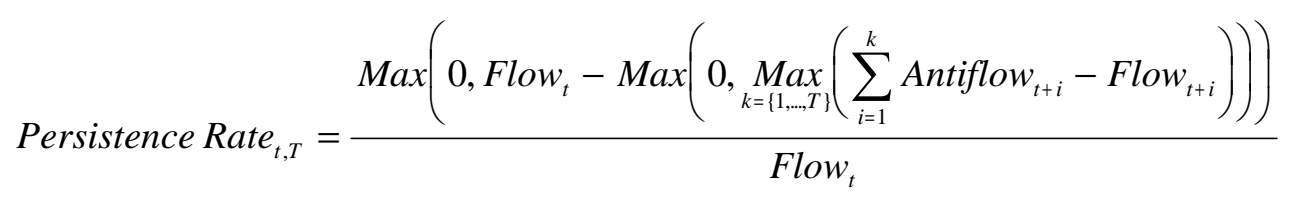

where Flow is job creation (job destruction) and AntiFlow is job destruction (job creation). For example, if job creation this period is 100 and employment changes over the next four periods $t+1$ to $t+4$ are: $-50,50,-25,0$, then four period persistent job creation would be 50 because over the four periods from $t+1$ to $t+4$ the plant always has an employment level at least 50 greater than it had in period $t-1$. In other words, 50 of the 100 jobs created in period $t$ are never destroyed in the four succeeding periods. The persistence rate would be 50/100 or 50\%.

One problem with the DHS persistence measure is that it only takes into account forward persistence. As a result, a job flow may be counted as persistent even though it just reverses a job flow from the previous period. For example, figure 8 shows a plant that destroys 5 jobs in period $t$, creates 5 jobs in period $t+1$ and neither creates nor destroys jobs thereafter. The 5 jobs destroyed in period $t$ are termed temporary because they are created again next period. But the 5 jobs created in period $t+1$ are deemed persistent even though they are just a reversal of the 5 jobs destroyed last period.

Another problem with the persistence rate measure is that the cut-off horizons are arbitrary, and it is difficult to know what the most appropriate persistence rate for measuring permanent changes is. Two years may not be sufficient for removing temporary cyclical increases and decreases in plants' employment levels. More generally, interpretation of persistence rates is difficult because there is no underlying statistical model. As a result, it is not always clear what assumptions about plants' employment changes underlie the measures.

Haltiwanger and Schuh (1999) identify as permanent those job flows that persist for 8 quarters. Using this definition, table 7 shows statistics for aggregate total job flows and 
permanent (persistent) job flows. Figure 9 depicts these two time series. ${ }^{23}$ Compared to the low frequency job flows estimated in section 3, persistent job flows are less smooth, larger, and vary more over the cycle. In both the mid 1970s and mid 1980s there are large changes in persistent job flows, but little change in low frequency (8 year cut-off) job flows. In this respect, persistent job flows are similar to low frequency job flows with a five year cut-off; their behavior reflects the inclusion of job flows with a period of less than 8 years.

\section{Cross Sectoral Job Flows}

The first studies of the relationship between reallocation and the business cycle focused on cross sectoral (industry) reallocation (Lilien, 1982). In part, this was due to data constraints. The only disaggregated time series data available were industry level. But this research focus was also probably due to the belief that shocks that changed the optimal allocation of resources in the economy were very likely highly correlated within an industry. Shifts in tastes and technology were likely to affect all plants within an industry producing a similar product with similar technology. Research into plant level reallocation by Davis and Haltiwanger (1990, 1992) altered this perception, and seemed to suggest the opposite conclusion- that reallocation shocks were almost entirely idiosyncratic. Common industry-level shocks seemed to be responsible for only a small part of the plant-level reallocation taking place in the economy.

The above evidence suggests that much of the plant-level reallocation documented by Davis and Haltiwanger was short-term in nature. The ability of the labor market to accommodate these high frequency changes in the distribution of productivities across plants testifies to its flexibility, but this flexibility is most likely produced by production workers moving across a stable stock of jobs, not by the destruction and creation of physical and organizational assets associated with more permanent job flows. And so the question remains whether this long-term reallocation is closely related to industry-level reallocation.

To explore this question I compute long-term job flows by 2 digit and 4 digit industries. First, I aggregate employment within industries. Instead of a panel of 20,000 plants, this yields a

\footnotetext{
${ }^{23}$ For plants that are not in consecutive ASM panels it is not possible to compute persistent job flows in years that are within 2 years of the end of the panel. Following Haltiwanger and Schuh (1999) I impute these rates by regressing the persistence rate of plants chosen at random to be a part of an ASM panel on the persistence rate of those plants that are chosen with certainty to be part of an ASM panel and the net increase in employment for that period. Regressions are run at the 4 digit level for each 2 digit industry.
} 
panel of 450 (4 digit) or 20 (2 digit) industries. Then, I apply a low pass filter to industry employment levels and compute industry level permanent job creation and permanent job destruction. $^{24}$ The industry level flows are then aggregated to arrive at total across industry permanent job flows.

4 digit industry-level reallocation is on average about 40 percent of total plant-level reallocation and 2 digit industry-level reallocation is about 30 percent, looking only at continuing plants, see table $8 .^{25}$ This contrasts with Davis and Haltiwanger (1992) who find that $99 \%$ of reallocation is within 2 digit industries and $88 \%$ within 4 digit industries. Davis and Haltiwanger emphasized the importance of within sector reallocation to avoid the Abraham and Katz (1986) criticism of Lilien (1982). By definition, differential responses of sectors to common shocks could not be responsible for the correlation of within sector reallocation with the cycle. The difference between the Davis and Haltiwanger measures of across industry reallocation and the results presented here owes to temporary reallocation. Davis and Haltiwanger compute reallocation as the sum of job creation and job destruction, and this includes many short-term job flows. Thus, while temporary reallocation is overwhelmingly a within sector phenomenon, permanent reallocation is not.

More strikingly, the cyclical behavior of cross sectoral NET is almost identical to total permanent NET; that is, nearly all of permanent job flows' contribution to aggregate employment fluctuations is due to cross sectoral job flows. For this to occur, industries that have increases in permanent job destruction in recessions must not also have increases in permanent job creation in a recoveries. Thus, while there is considerable within industry permanent job creation and permanent job destruction, these flows do not vary much over the cycle. Again, this contrasts with results from Davis and Haltiwanger, who report that within industry (or idiosyncratic) factors account for almost all of the cyclical variation in reallocation. As before, the source of the difference is that I consider only long-term job flows, while Davis and Haltiwanger do not.

The cyclical behavior of cross sectoral permanent job flows is very similar to overall permanent job flows, see figure 10 and table 8, though there are some differences. Not including births and deaths, cross sectoral job creation accounts for about 10\% (2 digit) and 30\% (4 digit)

\footnotetext{
${ }^{24}$ The approach is similar to that of Neumann and Topel (1991).

${ }^{25}$ Including births and deaths in long-term job flows does not alter the share of 2 digit flows.
} 
of permanent job creation. Cross sectoral job creation is pro-cyclical, but fluctuates less over the cycle than total permanent job creation. 2 digit cross sectoral job creation, for example, accounts for around $50 \%$ of the cyclical change in total permanent job creation between above and below average employment growth periods. Cross sectoral job destruction accounts for about $40 \%$ (2 digit) and 50\% (4 digit) of permanent job destruction, is counter-cyclical, and is even more sensitive to the cycle than total permanent job destruction. 2 digit cross sectoral job destruction, for example, accounts for about $120 \%$ of the cyclical change in permanent job destruction.

The early 1980s recessions highlight the different cyclical behavior of cross industry permanent job creation and destruction. Cross sectoral job destruction rises sharply during this period, but cross sectoral job creation falls only modestly. Because job flows are bounded below by zero, cross sectoral job creation could not fall by as much as job destruction rose in the early 1980s. The 1980s decline in trend manufacturing employment growth lowered mean job creation and, by bringing it closer to its lower bound, reduced the amount by which it could respond to adverse shocks. As a result, the inverse relationship between trend employment growth and the ratio of the variance of job destruction to the variance of job creation first documented by Foote (1998) is stronger for cross sectoral job flows, or job flows computed at higher levels of aggregation, than for total permanent job flows. The ratio of the standard deviation of 2 digit cross sectoral job destruction to the standard deviation of 2 digit cross sectoral job creation is 4.3 , compared to 3.7 for 4 digit flows, and 2.3 for total permanent job flows. Trend growth rates for all three levels of aggregation are, of course, the same.

\section{Conclusion}

Whether reallocation in the form of permanent job flows is concentrated cyclically has important implications for our understanding of business cycles. This paper has shown that permanent job destruction is concentrated in downturns, accounting for approximately 30 percent of the increase in job destruction that occurs over the cycle. Permanent job creation is also cyclically related, and together the two flows account for approximately 30 percent of the cyclical change in aggregate employment over the cycle.

The plant-level permanent employment movements reported in this paper also provide information about the reallocation process. First, movements in employment across sectors are a significant contributor to total plant-level reallocation and the predominant determinant of 
cyclical fluctuations in reallocation. This contrasts with the results from Davis and Haltiwanger (1992) who, because of problems identifying cross sectional reallocation stressed the importance of within sector reallocation. Second, the temporal separation of job creation and job destruction implies that reallocation is a protracted process. This time consuming aspect of reallocation is also emphasized by Loungani and Rogerson (1989), who show that permanent industry switchers have longer unemployment spells that non-industry switchers. Caballero and Hammour (1996) show that this decoupling of permanent job flows may also indicate inefficiencies in the reallocation process. Third, although births and deaths are a relatively small fraction of total job flows, they are an extremely important component, about 50\%, of permanent job flows. Their impact on aggregate employment fluctuations is also similar to that of permanent job flows of continuing plants.

Because the identification of reallocation related job flows in this paper relies on a cutoff period that separates permanent from non-permanent job flows, one can see how the estimated impact of reallocation changes as this cut-off is changed. The difference between the results for 5 and 8 year cut-offs reveals that the impact can be substantial. Because this difference is accounted for by within-plant job flows with a period between 5 and 8 years, less than the cut-off that much of the literature has established for cyclical fluctuations, this paper chooses to emphasize results from the 8 year cut-off. But such an identification implies that much of the cyclical movements in employment unrelated to restructuring can be quite drawn out, as plants take several years to completely reverse the effects of cyclical shocks.

Despite the similarity of the overall results with previous studies, some aspects of reallocation described in this paper differ significantly from previous analyses of reallocation and the cycle. Most noticeably, this paper estimates that reallocation was particularly important during the recessions of the early 1980s. In contrast, papers using the dispersion of stock market returns as an indicator of reallocation stressed the 1974-75 recession as being particularly important. Some of this difference may be due to differences in industry coverage. This paper only looks at manufacturing, where industries such as steel did undergo major restructuring in the early 1980s. Different methods of identifying reallocation may also be responsible for the different emphasis.

The cause of the correlation between reallocation and the cycle is still an open question. 
It is possible that shocks to plants' relative productivities are cyclically correlated. Or it could be that aggregate shocks affect the benefits and costs of reallocation differently and therefore affect decisions to permanently increase or decrease employment. The research that has tried to distinguish between reallocation shocks and reallocation timing has used highly aggregated variables, such as sectoral rates of return (Brainard and Cutler, 1993) or manufacturing's employment share (Campbell and Kuttner, 1996). Focusing on plant-level variables is an unexploited alternative strategy. With data on the timing of plant-level permanent employment changes, one can see whether plant-level shocks to productivity or profitability pre-dated these changes, as one would expect if reallocation timing were present, or did not, as one would expect if reallocation shocks drive cycles. Also, given differences across industries in their sensitivity to the cycle, one can see whether permanent job flows vary more over the cycle in those industries that are more cyclically sensitive, as one would expect with some models of reallocation timing.

Finally, the fact that a large majority of job flows are not long-term indicates that reallocation can explain only a part of the behavior of aggregate job flows. Figura (2002) describes the cyclical behavior of both the short-term and long-term components of job flows. Future research on the separate behavior of these flows can help economists better understand the sources of aggregate employment fluctuations. 


\section{References}

Abraham, Katherine and Lawrence Katz, "Cyclical Unemployment: Sectoral Shifts of Aggregate Disturbances?” Journal of Political Economy 94, no 6. (1986): 507-22.

Andolfatto, David, "Business Cycles and Labor Market Search," American Economic Review 86, no.1 (1996): 112-32.

Atkeson, Andrew and Patrick J. Kehoe, "Measuring Organization Capital," NBER Working Paper no. 8722, 2002.

Baily, Martin, Eric Bartelsman and John Haltiwanger, "Labor Productivity: Structural Change and Cyclical Dynamics,” Working Paper, University of Maryland, 1998.

Bar Levi, Gadi, “The Sullying Effect of Recessions,” Working Paper, Northwestern University, 1998.

Baxter, Marianne and Robert G. King, "Measuring Business Cycles: Approximate Band-Pass filters for Economic Time Series," The Review of Economics and Statistics 81, no. 4 (1999): 575-93.

Brainard, Lael and David M. Cutler, "Sectoral Shifts and Cyclical Unemployment Reconsidered," Quarterly Journal of Economics 108, no. 1 (1993): 219-43.

Burns, Arthur, and Wesley C. Mitchell, Measuring Business Cycles, New York: National Bureau of Economic Research, 1946.

Caballero, Ricardo and Mohamad Hammour (1996) "On the Timing and Efficiency of Creative Destruction," Quarterly Journal of Economics, 111(3), 805-852.

Campbell, Jeffrey R. and Kenneth N. Kuttner, "Macroeconomic Effects of Employment Reallocation," Carnegie-Rochester Conference Series on Public Policy 44 (1996): 87116.

Christiano Lawrence J. and Terry J. Fitzgerald, "The Band Pass Filter," NBER Working Paper no. 7257,1999 .

Davis, Steven, "Fluctuations in the Pace of Labor Reallocations", Carnegie-Rochester Conference Series on Public Policy 27 (1987): 335-402.

Davis, Steven and John Haltiwanger, "Gross Job Creation and Destruction: Microeconomic Evidence and Macroeconomic Implications", NBER Macroeconomics Annual 5 (1990): 123-68. 
, “Gross Job Creation, Gross Job Destruction, and Employment Reallocation,” Quarterly Journal of Economics 107, no. 3 (1992): 819-63.

, "On the Driving Forces Behind Cyclical Movements in Employment and Job

Reallocation," American Economic Review 89, no. 5 (1999): 1234-1258.

Davis, Steven, John Haltiwanger, and Scott Schuh. Job Creation and Destruction, Cambridge, MA: MIT Press, 1996.

Den Haan, Wouter, Gary Ramey and Joel Watson, "Job Destruction and Propagation of Shocks," American Economic Review 90, no. 3 (2000): 482-498.

Dunne, Timothy, Mark J. Roberts and Larry Samuelson, "Plant Turnover and Gross Employment Flows in the U.S. Manufacturing Sector," Journal of Labor Economics 7, no. 1 (1989): 48-71.

Faust, Jon and Eric Leeper, "When do Long-Run Identifying Restrictions Give Reliable Results?" Journal of Business and Economic Statistics 15, no.3 (1997): 345-353.

Figura, J. Andrew, "The Cyclical Behavior of Short-term and Long-term Job Flows," FEDS Working Paper No. 2002-12, Board of Governors of the Federal Reserve System, 2002.

Foote, Christopher L., "Trend Employment Growth and the Bunching of Job Creation and Destruction," Quarterly Journal of Economics 113, no. 3 (1998): 809-34.

Haltiwanger, John and Scott Schuh, "Gross Flows Between Plants and Industries," New England Economic Review, March/April (1999): 41-64.

Harvey, Andrew, Time Series Models, Cambridge, MA: MIT Press, 1993.

Jacobson, Louis S., Lalonde, Robert J. and Daniel G. Sullivan, "Earnings Losses of Displaced Workers," American Economic Review 83, no. 4(1993): 685-709.

Lilien, David, “Sectoral Shifts and Cyclical Unemployment," Journal of Political Economy 90, no. 4 (1982): 777-93.

Loungani, Prakash and Richard Rogerson, "Cyclical Fluctuations and the Sectoral Reallocation of Labor: Evidence from the PSID," Journal of Monetary Economics 23, no. 2 (1989): 259-273.

Loungani, Prakash, Mark Rush and William Tave, "Stock Market Dispersion and Unemployment," Journal of Monetary Economics 25, no. 3 (1990): 367-88. 
Loungani, Prakash, "Macroeconomic Effects of Labor Reallocation: A Comment," CarnegieRochester Conference Series on Public Policy 44 (1996): 117-124.

Merz, Monica, "Search in the Labor Market and the Real Business Cycle," Journal of Monetary Economics 36, no. 2 (1995): 269-300.

Murphy, Kevin M. and Robert Topel, "The Evolution of Unemployment in the United States: 1968-1985," NBER Macroeconomics Annual 2 (1987): 11-58.

Neumann, George R. and Robert H. Topel, "Employment Risk, Diversification, and Unemployment," Quarterly Journal of Economics 106, no. 4 (1991): 1341-1365.

Prescott, Edward C. and Michael Visscher (1980) "Organization Capital," Journal of Political Economy, 88(3), pp. 446-461.

Priestly, M. B. (1981) Spectral Analysis and Time Series, Boston: Harcourt Brace \& Co.

Ramey, Valerie A. and Matthew D. Shapiro, "Displaced Capital," NBER Working Paper 6775, (1998).

Spletzer, James R., "The Contribution of Establishment Births and Deaths to Employment Growth," Journal of Business \& Economic Statistics 18, no. 1 (2000): 113-125.

Starr-McCluer, Martha, "Cyclical Fluctuations and Sectoral Reallocation: A Reexamination," Journal of Monetary Economics 31 (1993): 417-25. 
Table 1. Job Flows at Different Frequencies and Cumulative Job Flows

Panel A. 1974-78

Job Creation

Year

1

2

3

4

Cum

Freq

6.28

Cum

15.48

8.65

24.45

11.45

30.75

14.27

36.82

Permanent Rate of Reallocation: 3.09

\section{Panel B. 1978-83}

Job Creation

Year

1

2

3

4

Cum

7.39

Freq

Job Destruction

SUM

7.39

Cum

Freq

9.38

9.38

20.12

15.34

32.26

22.32

46.29

30.70

Cum

21.76

17.03

40.52

25.69

56.13

28.27

71.18

31.02

SUM

Freq

21.76

$\begin{array}{lllllll}2 & 13.07 & 8.29 & 20.12 & 15.34 & 33.19 & 23.63 \\ 3 & 18.13 & 8.19 & 32.26 & 22.32 & 50.39 & 30.51 \\ 4 & 23.26 & 7.67 & 46.29 & 30.70 & 69.55 & 38.37\end{array}$

Permanent Rate of Reallocation: 7.20

\section{Panel C. 1984-88}

Job Creation

Year

1

2

3

4

Cum

Freq

Job Destruction

SUM

$\begin{array}{ccccccc}\text { Cum } & \text { Freq } & \text { Cum } & \text { Freq } & \text { Cum } & \text { Freq } \\ 1 & 8.35 & 8.35 & 8.14 & 8.14 & 16.49 & 16.49 \\ 3 & 14.77 & 10.12 & 18.01 & 13.36 & 32.78 & 23.47 \\ 4 & 21.33 & 11.53 & 26.39 & 16.59 & 47.72 & 28.11 \\ 29.12 & 13.68 & 33.36 & 17.93 & 62.48 & 31.61 \\ & & & \end{array}$




\section{Panel D. 1989-93}

Job Creation

Job Destruction

Year

1

2

3

4

Cum

Freq

Cum

Freq

5.03

5.03

14.00

10.74

20.79

13.31

27.25

15.67

12.62

24.19

Permanent Rate of Reallocation: 5.10

Panel E. Average Across Panels

Job Creation

Year

1

2

3

4
Job Destruction

Cum

9.51

19.14

27.55

35.93

Permanent Rate of Reallocation: 5.08

Note: Cum stands for the cumulative measure of job flows, and Freq stands for the frequency measure. 
Table 2. Comparison of Job Flows from the ASM and Overlapping 7 Year Panels

Panel A. Job Flows from the Complete ASM

\begin{tabular}{lcccc} 
& Job Creation & Job Destruction & NET & SUM \\
\hline Mean & 5.04 & 5.57 & -0.53 & 10.62 \\
Standard Deviation & 0.88 & 1.67 & 2.01 & 1.75 \\
Maximum & 7.32 & 11.42 & 2.55 & 14.67 \\
Minimum & 3.25 & 3.32 & -8.17 & 6.91
\end{tabular}

Panel B. Job Flows from the Overlapping 7 Year Panels

\begin{tabular}{lcccc} 
& Job Creation & Job Destruction & NET & SUM \\
\hline Mean & 4.06 & 4.41 & -0.35 & 8.47 \\
Standard Deviation & 0.93 & 1.48 & 1.93 & 1.53 \\
Maximum & 6.91 & 10.80 & 2.73 & 12.93 \\
Minimum & 2.13 & 2.24 & -8.67 & 4.90 \\
Correlation with & & & & \\
Complete ASM & 0.83 & 0.92 & 0.96 & 0.81 \\
Flow & & & &
\end{tabular}




\section{Table 3. Low Frequency Job Flows}

\section{Panel A. Overall Statistics}

\begin{tabular}{lcccc||cccc} 
& \multicolumn{3}{c}{ Permanent Job Flows- 8 Year } & \multicolumn{3}{c}{ Permanent Job Flows- 5 Year } \\
& JC & JD & NET & SUM & JC & JD & NET & SUM \\
\cline { 2 - 7 } Mean & 0.60 & 0.94 & -0.35 & 1.54 & 0.83 & 1.17 & -0.34 & 2.00 \\
Std. Dev. & 0.10 & 0.23 & 0.32 & 0.17 & 0.24 & 0.36 & 0.57 & 0.21 \\
Share of Total Job & 14.70 & 21.05 & 81.52 & 18.03 & 20.47 & 26.12 & 79.89 & 23.44 \\
Flows & & & & & & & &
\end{tabular}

\section{Panel B. Job Flows During Above and Below Average Employment Growth Periods}

\begin{tabular}{lcccc||cccc} 
& \multicolumn{3}{c}{ Permanent Job Flows- 8 Year } & \multicolumn{3}{c}{ Permanent Job Flows- 5 Year } \\
& JC & JD & NET & SUM & JC & JD & NET & SUM \\
\cline { 2 - 8 } Above Mean & 0.63 & 0.84 & -0.20 & 1.47 & 0.98 & 0.93 & 0.04 & 1.91 \\
Below Mean & 0.56 & 1.05 & -0.49 & 1.61 & 0.68 & 1.42 & -0.74 & 2.09 \\
Difference & 0.08 & -0.21 & 0.29 & -0.14 & 0.30 & -0.48 & 0.78 & -0.19 \\
Difference as Share & 18.32 & 14.13 & 15.05 & 12.48 & 70.04 & 32.14 & 40.47 & 17.27
\end{tabular}

\section{Panel C. Job Flows During Expansions and Recessions}

\begin{tabular}{lcccc||cccc} 
& \multicolumn{3}{c}{ Permanent Job Flows- 8 Year } & \multicolumn{3}{c}{ Permanent Job Flows- 5 Year } \\
& JC & JD & NET & SUM & JC & JD & NET & SUM \\
\cline { 2 - 7 } Expansion Mean & 0.62 & 0.89 & -0.26 & 1.51 & 0.89 & 1.07 & -0.18 & 1.96 \\
Recession Mean & 0.50 & 1.15 & -0.65 & 1.64 & 0.61 & 1.52 & -0.91 & 2.14 \\
Difference & 0.13 & -0.26 & 0.39 & -0.13 & 0.28 & -0.45 & 0.73 & -0.17 \\
Difference as Share & 14.09 & 12.14 & 12.71 & 10.72 & 30.63 & 20.97 & 23.83 & 13.96
\end{tabular}

Note: JC is job creation, JD is job destruction, NET is JC-JD, and SUM is JC+JD. "Difference" refers to the difference between mean job flows during expansions/above average growth periods and recessions/below average growth periods. "Difference as share" is the ratio between difference for the job flow in question and difference for total job flows. 


\section{Table 4. Births and Deaths}

\section{A. Overall Statistics}

Mean

\begin{tabular}{cccc}
\multicolumn{5}{c}{ Births and Deaths } \\
JC & JD & NET & SUM \\
\hline 0.56 & 0.79 & -0.23 & 1.35
\end{tabular}

Std. Dev.

0.26

0.30

0.38

0.42

Share of Total Job Flows

10.86

14.10

55.70

12.54

\section{B. Above and Below Average Employment Growth Periods}

\begin{tabular}{lcccc} 
& \multicolumn{4}{c}{ Births and Deaths } \\
& JC & JD & NET & SUM \\
\cline { 2 - 5 } Above Mean & 0.63 & 0.65 & -0.01 & 1.28 \\
Below Mean & 0.50 & 0.93 & -0.43 & 1.43 \\
Difference & 0.14 & -0.28 & 0.42 & -0.15 \\
Difference as Share & 34.39 & 18.15 & 21.44 & 12.65
\end{tabular}

\section{Expansions and Recessions}

Expansion Mean

Recession Mean

Difference

Difference as Share

\begin{tabular}{cccc}
\multicolumn{4}{c}{ Births and Deaths } \\
JC & JD & NET & SUM \\
\hline 0.61 & 0.75 & -0.14 & 1.35 \\
0.48 & 0.87 & -0.39 & 1.35 \\
0.12 & -0.12 & 0.24 & 0.00 \\
16.93 & 9.88 & 12.52 & -0.60
\end{tabular}

Note: JC is job creation, JD is job destruction, NET is JC-JD, and SUM is JC+JD. "Difference" refers to the difference between mean job flows during expansions/above average growth periods and recessions/below average growth periods. "Difference as share" is the ratio between difference for the job flow in question and difference for total job flows. 
Table 5. Permanent Job Flows (8 year cut-off) Including Birth/Deaths

Panel A. Overall Statistics

\begin{tabular}{lcccc} 
& \multicolumn{4}{c}{ Permanent Job Flows } \\
& JC & JD & NET & SUM \\
\cline { 2 - 5 } Mean & 1.15 & 1.75 & -0.59 & 2.90 \\
Std. Dev. & 0.28 & 0.42 & 0.51 & 0.50 \\
Share of Total Job Flows & 25.17 & 33.21 & 88.39 & 29.47
\end{tabular}

Panel B. Above and Below Average Employment Growth Periods

Permanent Job Flows

Above Mean

\begin{tabular}{cccc} 
JC & JD & NET & SUM \\
\hline 1.23 & 1.51 & -0.28 & 2.74
\end{tabular}

Below Mean

1.08

1.99

$-0.91$

3.07

Difference

0.15

$-0.48$

0.63

$-0.33$

Difference as Share

29.97

27.09

27.72

25.96

Panel C. Expansions and Recessions

\begin{tabular}{lcccc} 
& \multicolumn{4}{c}{ Permanent Job Flows } \\
& JC & JD & NET & SUM \\
\cline { 2 - 5 } Expansion Mean & 1.19 & 1.65 & -0.46 & 2.83 \\
Recession Mean & 1.04 & 2.11 & -1.07 & 3.14 \\
Difference & 0.15 & -0.46 & 0.61 & -0.31 \\
Difference as Share & 16.20 & 19.72 & 18.72 & 22.03
\end{tabular}

Note: JC is job creation, JD is job destruction, NET is JC-JD, and SUM is JC+JD. "Difference" refers to the difference between mean job flows during expansions/above average growth periods and recessions/below average growth periods. "Difference as share" is the ratio between difference for the job flow in question and difference for total job flows. 
Table 6. Combined Baxter-King and Births/Deaths using Actual Employment Shares Panel A. Overall Statistics

\begin{tabular}{lcccc} 
& \multicolumn{4}{c}{ Permanent Job Flows } \\
& JC & JD & NET & SUM \\
\cline { 2 - 5 } Mean & 1.21 & 1.78 & -0.57 & 2.99 \\
Std. Dev. & 0.30 & 0.42 & 0.53 & 0.50 \\
Share of Total Job Flows & 26.35 & 33.86 & 85.36 & 30.36
\end{tabular}

Panel B. Above and Below Average Employment Growth Periods

Permanent Job Flows

\begin{tabular}{lcccc} 
& JC & JD & NET & SUM \\
\cline { 2 - 5 } Above Mean & 1.29 & 1.54 & -0.25 & 2.83 \\
Below Mean & 1.12 & 2.03 & -0.90 & 3.15 \\
Difference & 0.17 & -0.49 & 0.66 & -0.32 \\
Difference as Share & 34.21 & 27.68 & 29.12 & 25.12
\end{tabular}

Panel C. Expansions and Recessions

\begin{tabular}{lcccc} 
& \multicolumn{4}{c}{ Permanent Job Flows } \\
& JC & JD & NET & SUM \\
\cline { 2 - 5 } Expansion Mean & 1.24 & 1.68 & -0.44 & 2.93 \\
Recession Mean & 1.08 & 2.13 & -1.05 & 3.21 \\
Difference & 0.16 & -0.44 & 0.61 & -0.28 \\
Difference as Share & 17.43 & 19.05 & 18.59 & 20.11
\end{tabular}

Note: JC is job creation, JD is job destruction, NET is JC-JD, and SUM is JC+JD. “ "Difference" refers to the difference between mean job flows during expansions/above average growth periods and recessions/below average growth periods. "Difference as share" is the ratio between difference for the job flow in question and difference for total job flows. 
Table 7. Persistent Job Flows

Panel A. Overall Statistics

Mean

\begin{tabular}{cccc} 
JC & JD & NET & SUM \\
\hline 1.47 & 2.22 & -0.75 & 3.69
\end{tabular}

Std. Dev.

0.49

1.03

1.13

1.15

Share of Total Job Flows

28.73

40.34

194.57

34.75

Panel B. Above and Below Average Employment Growth Periods

\begin{tabular}{lcccc}
\hline & \multicolumn{3}{c}{8 Quarter Persistent Job Flows } \\
& JC & JD & NET & SUM \\
\cline { 2 - 5 } Above Mean & 1.50 & 1.82 & -0.32 & 3.32 \\
Below Mean & 1.44 & 2.63 & -1.19 & 4.07 \\
Difference & 0.06 & -0.81 & 0.87 & -0.75 \\
Difference as Share & 13.85 & 51.87 & 43.85 & 65.76 \\
& & & & \\
Panel C. Expansions and Recessions & & & \\
\hline & & & & \\
& JC & JD & NET & 3.58 \\
Expansion Mean & 1.57 & 2.02 & -0.45 & 3.99 \\
Recession Mean & 1.21 & 2.78 & -1.58 & -0.40 \\
Difference & 0.36 & -0.76 & 1.12 & 33.37 \\
Difference as Share & 59.30 & 42.01 & 46.33 &
\end{tabular}

Note: JC is job creation, JD is job destruction, NET is JC-JD, and SUM is JC+JD. "Difference" refers to the difference between mean job flows during expansions/above average growth periods and recessions/below average growth periods. "Difference as share" is the ratio between difference for the job flow in question and difference for total job flows. 


\section{Table 8. Cross Sectoral Job Flows}

Panel A. Overall Statistics

\begin{tabular}{|c|c|c|c|c|c|c|c|c|}
\hline & \multicolumn{4}{|c|}{$\begin{array}{l}\text { Permanent Cross Sectoral } \\
\text { Job Flows ( } 2 \text { digit })\end{array}$} & \multicolumn{4}{|c|}{$\begin{array}{l}\text { Permanent Cross Sectoral } \\
\text { Job Flows (4 digit) }\end{array}$} \\
\hline & $\mathrm{JC}$ & JD & NET & SUM & $\mathrm{JC}$ & JD & NET & SUM \\
\hline Mean & 0.06 & 0.40 & -0.34 & 0.46 & 0.16 & 0.50 & -0.34 & 0.66 \\
\hline Std. Dev. & 0.06 & 0.28 & 0.33 & 0.24 & 0.07 & 0.27 & 0.33 & 0.22 \\
\hline $\begin{array}{l}\text { Share of Total } \\
\text { Permanent Job Flows }\end{array}$ & 9.71 & 42.42 & 98.49 & 29.76 & 27.04 & 53.44 & 98.69 & 43.22 \\
\hline
\end{tabular}

Panel B. Above and Below Average Employment Growth Periods

Permanent Cross Sectoral Job Flows (2 digit)
Permanent Cross Sectoral Job Flows (4 digit)

\begin{tabular}{lcccc||cccc} 
& JC & JD & NET & \multicolumn{1}{c}{ SUM } & JC & JD & NET & SUM \\
\cline { 2 - 8 } Above Mean & 0.08 & 0.27 & -0.19 & 0.35 & 0.19 & 0.38 & -0.19 & 0.58 \\
Below Mean & 0.04 & 0.52 & -0.48 & 0.55 & 0.13 & 0.61 & -0.48 & 0.74 \\
Difference & 0.04 & -0.25 & 0.29 & -0.21 & 0.06 & -0.23 & 0.28 & -0.17 \\
Difference as Share & 50.04 & 116.05 & 98.38 & 154.06 & 76.76 & 105.58 & 97.87 & 122.17
\end{tabular}

\section{Panel C. Expansions and Recessions}

\begin{tabular}{lcccc||cccc} 
& \multicolumn{3}{c}{ Permanent Cross Sectoral } & \multicolumn{3}{c}{ Permanent Cross Sectoral } \\
& \multicolumn{3}{c}{ Job Flows (2 digit) } & \multicolumn{3}{c}{ Job Flows (4 digit) } \\
\cline { 2 - 9 } & JC & JD & NET & SUM & JC & JD & NET & SUM \\
\cline { 2 - 10 } Expansion Mean & 0.07 & 0.33 & -0.27 & 0.40 & 0.18 & 0.44 & -0.27 & 0.62 \\
Recession Mean & 0.01 & 0.71 & -0.70 & 0.72 & 0.09 & 0.79 & -0.70 & 0.88 \\
Difference & 0.06 & -0.38 & 0.44 & -0.32 & 0.09 & -0.35 & 0.44 & -0.26 \\
Difference as Share & 45.39 & 127.40 & 102.83 & 188.71 & 68.66 & 117.56 & 102.91 & 154.12
\end{tabular}

Note: JC is job creation, JD is job destruction, NET is JC-JD, and SUM is JC+JD. "Difference" refers to the difference between mean job flows during expansions/above average growth periods and recessions/below average growth periods. "Difference as share" is the ratio between difference for the job flow in question and difference for total permanent job flows. 
Figure 1. Job Flows at Different Frequencies and Cumulative Job Flows-Averages Across ASM Panels

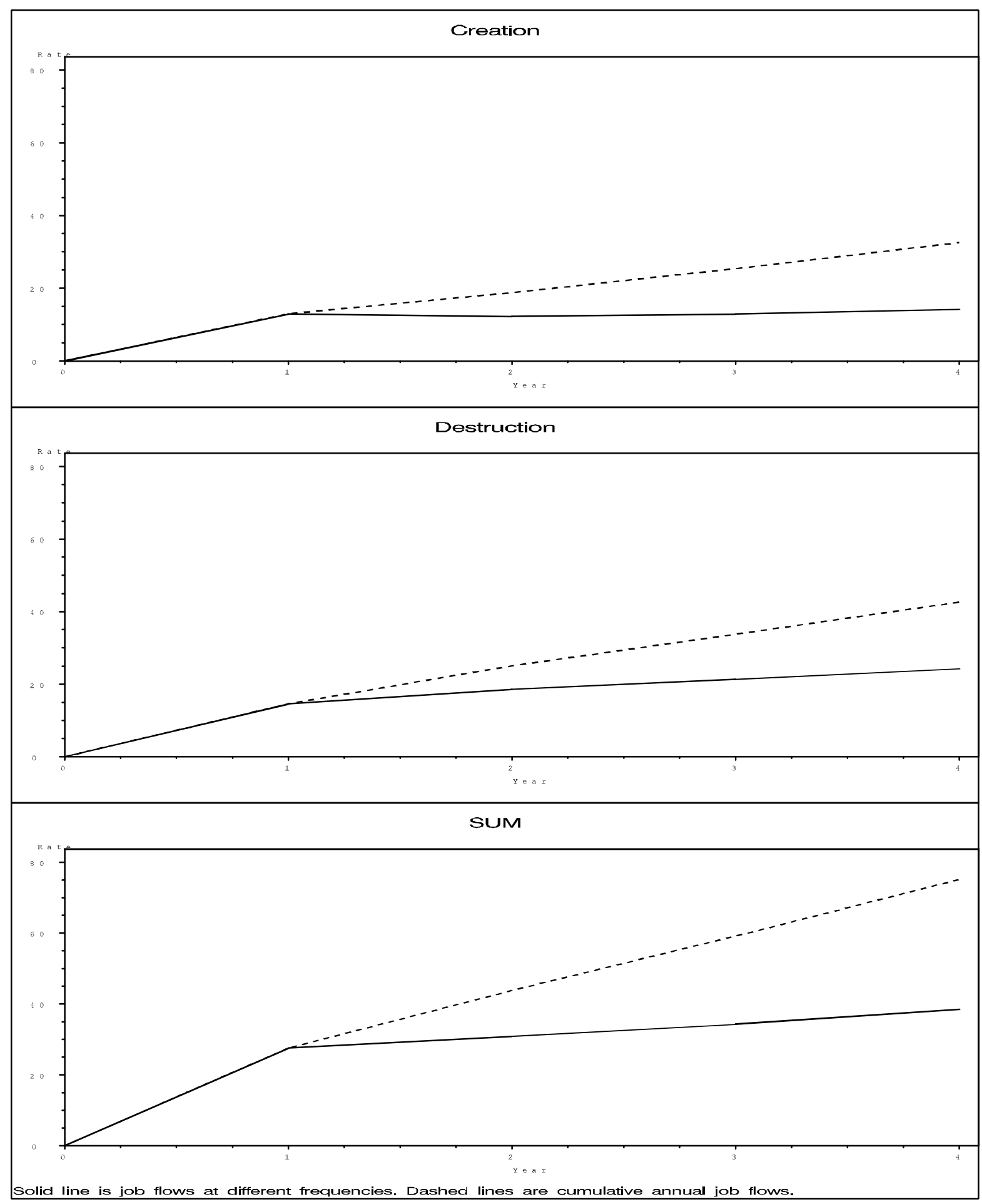

$-38-$ 
Figure 2. Permanent (Low Frequency) Job Flows

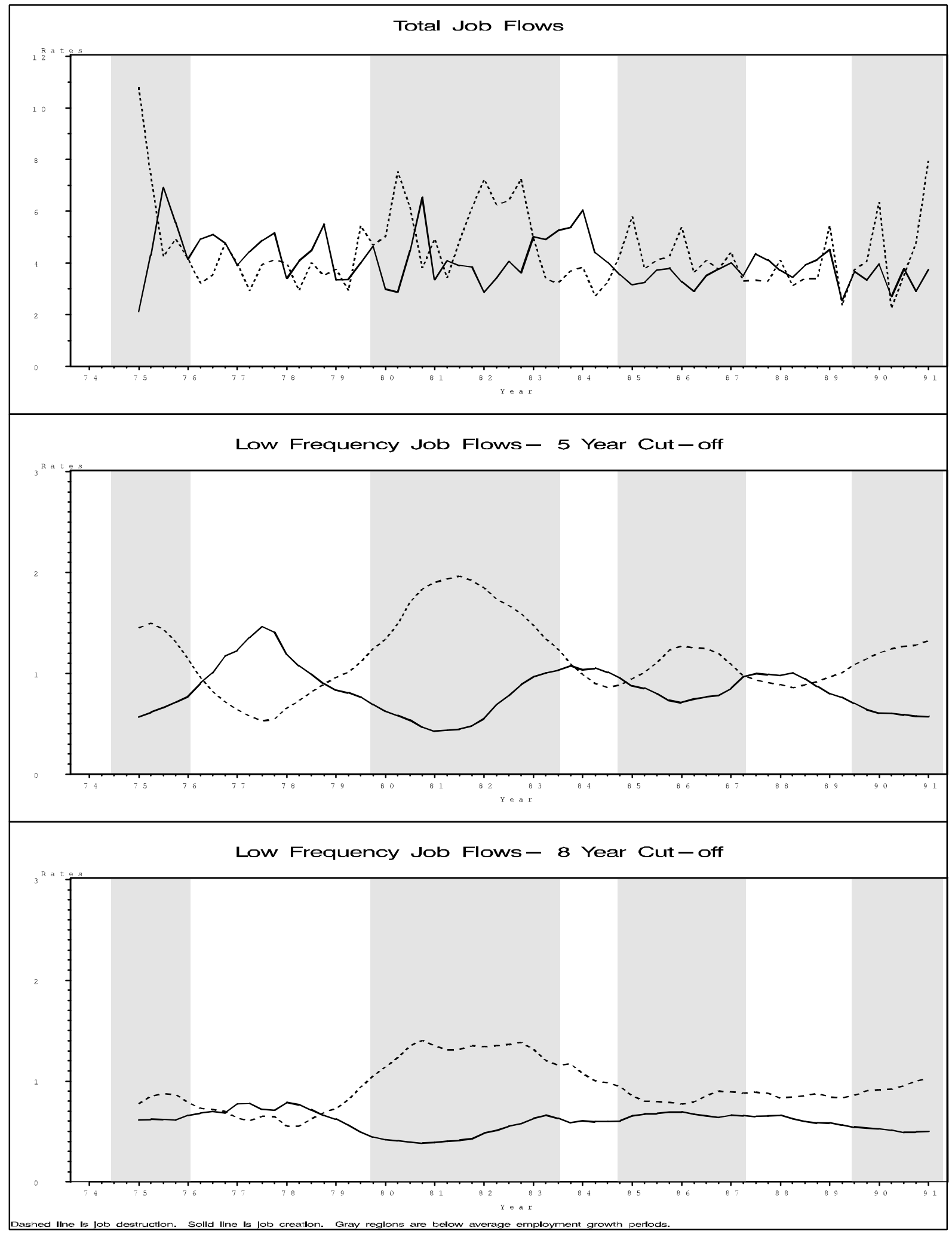


Figure 3. Births and Deaths

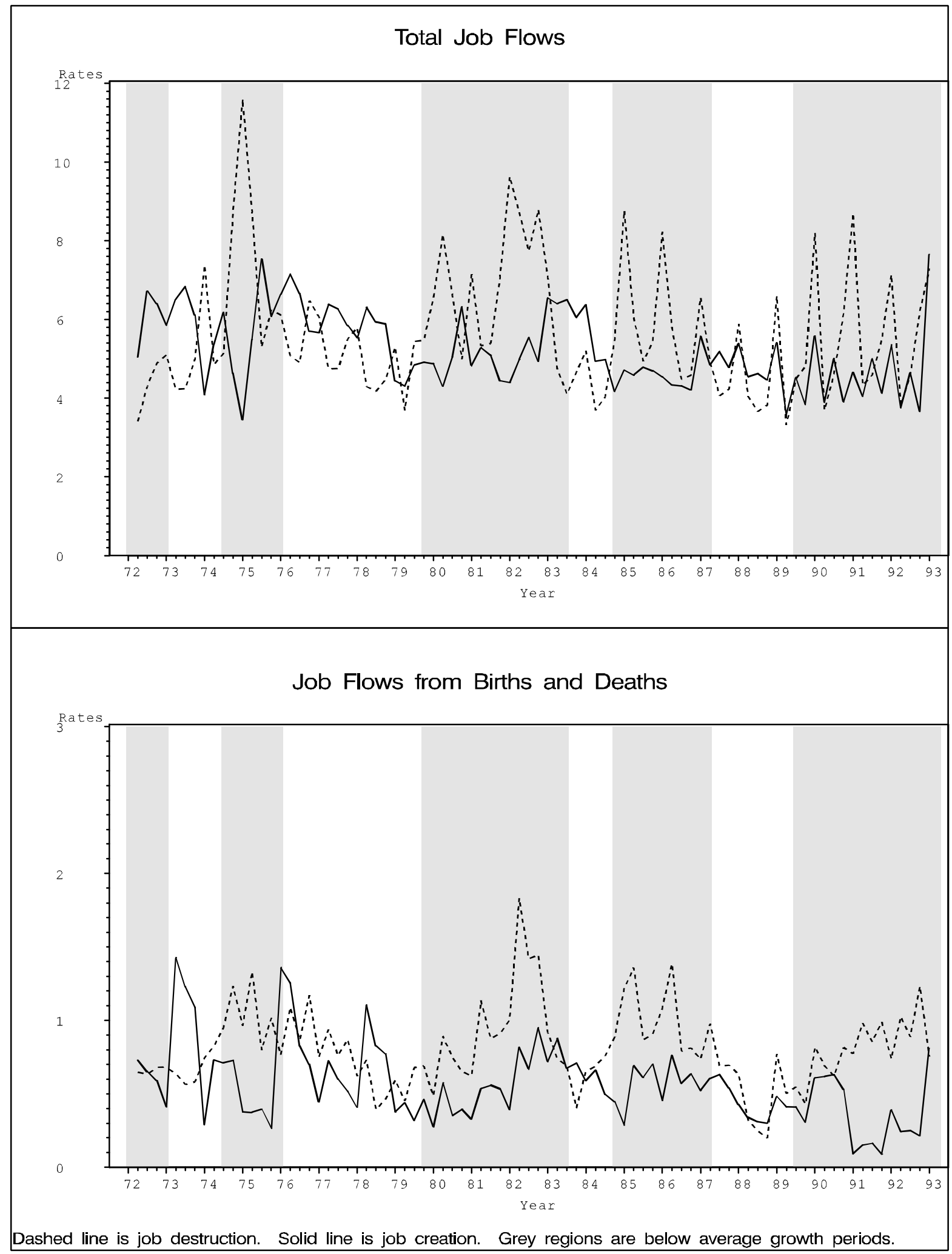


Figure 4. Permanent Job Flows Including Births/Deaths

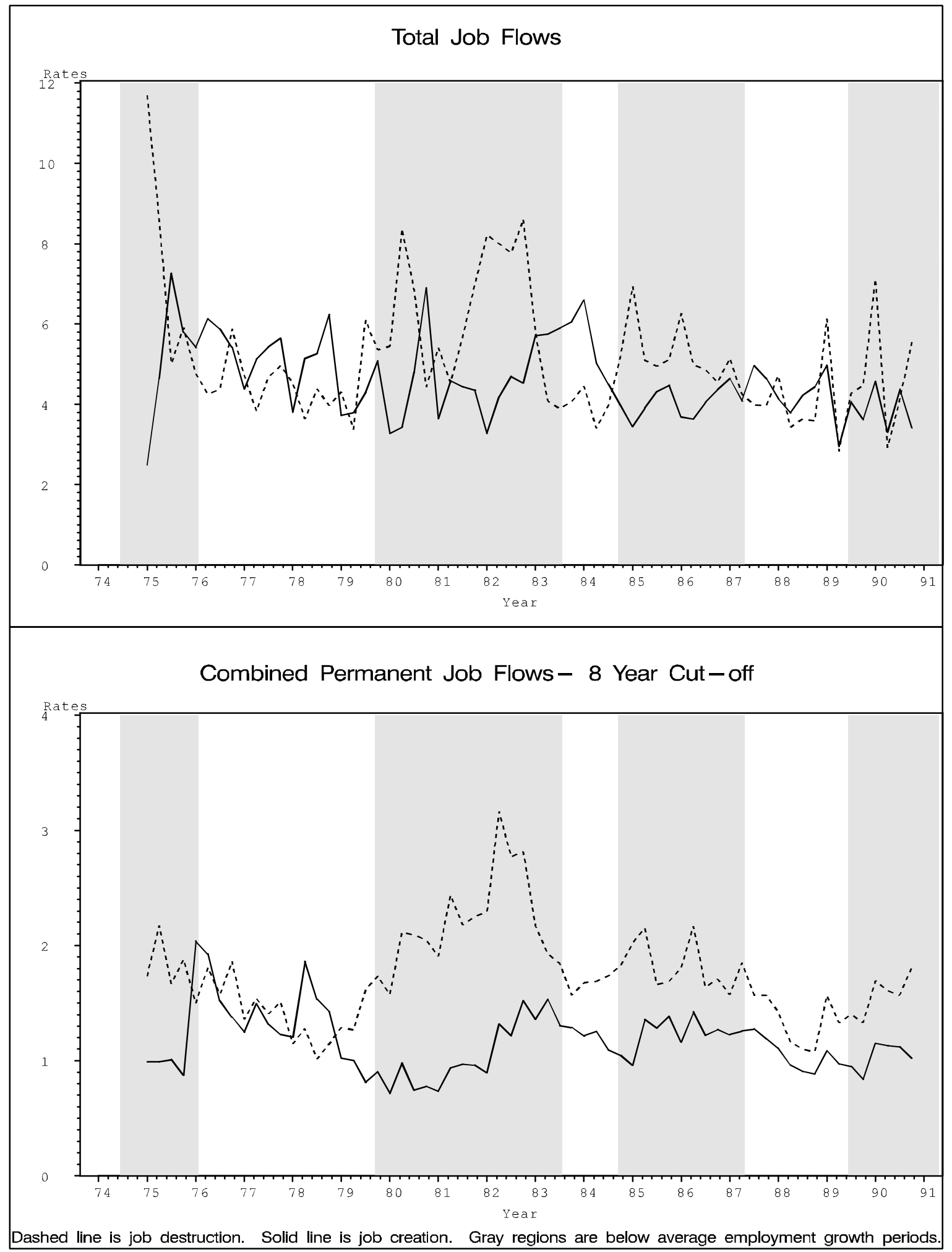


Figure 5. Permanent Job Flows of Small, Medium, and Large Plants

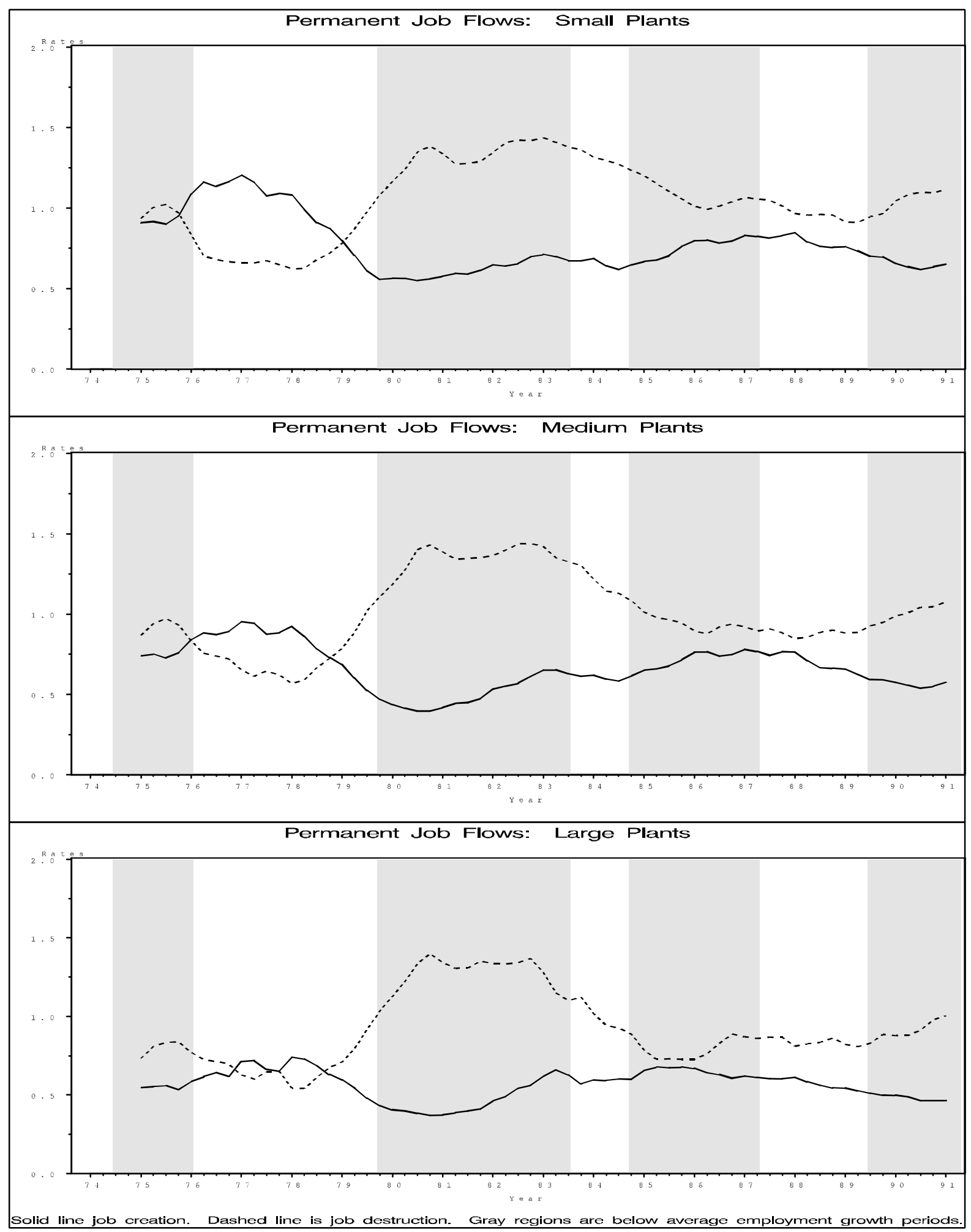


Figure 6. Permanent Job Flows weighted by Panel Shares and ASM Shares
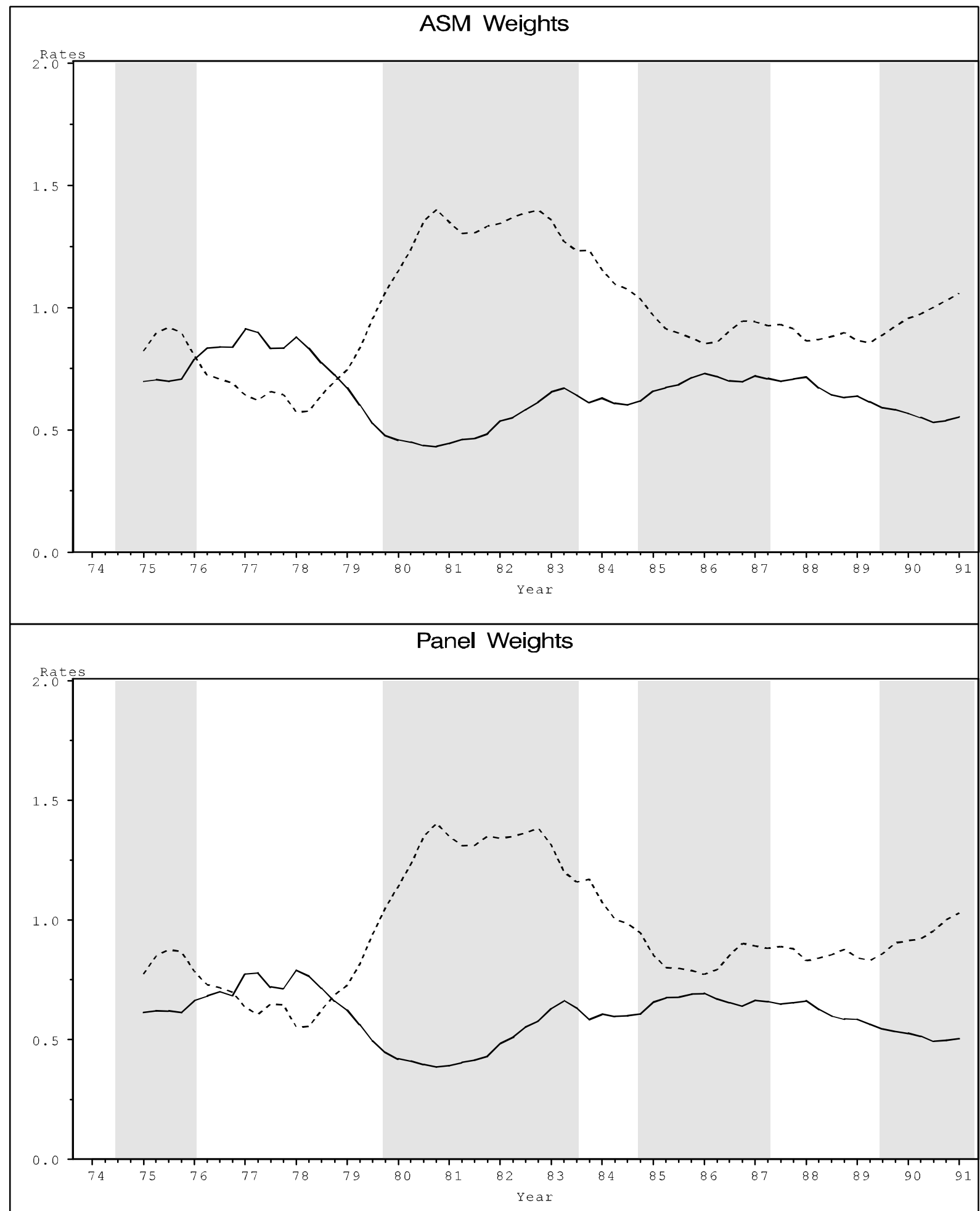

Solid line job creation. Dashed line is job destruction. Gray regions are below average employment growth periods. 
Figure 7. Weights in the Frequency Domain for an 11 Quarter Forward and Backward Filter with an 8 year Cut-off

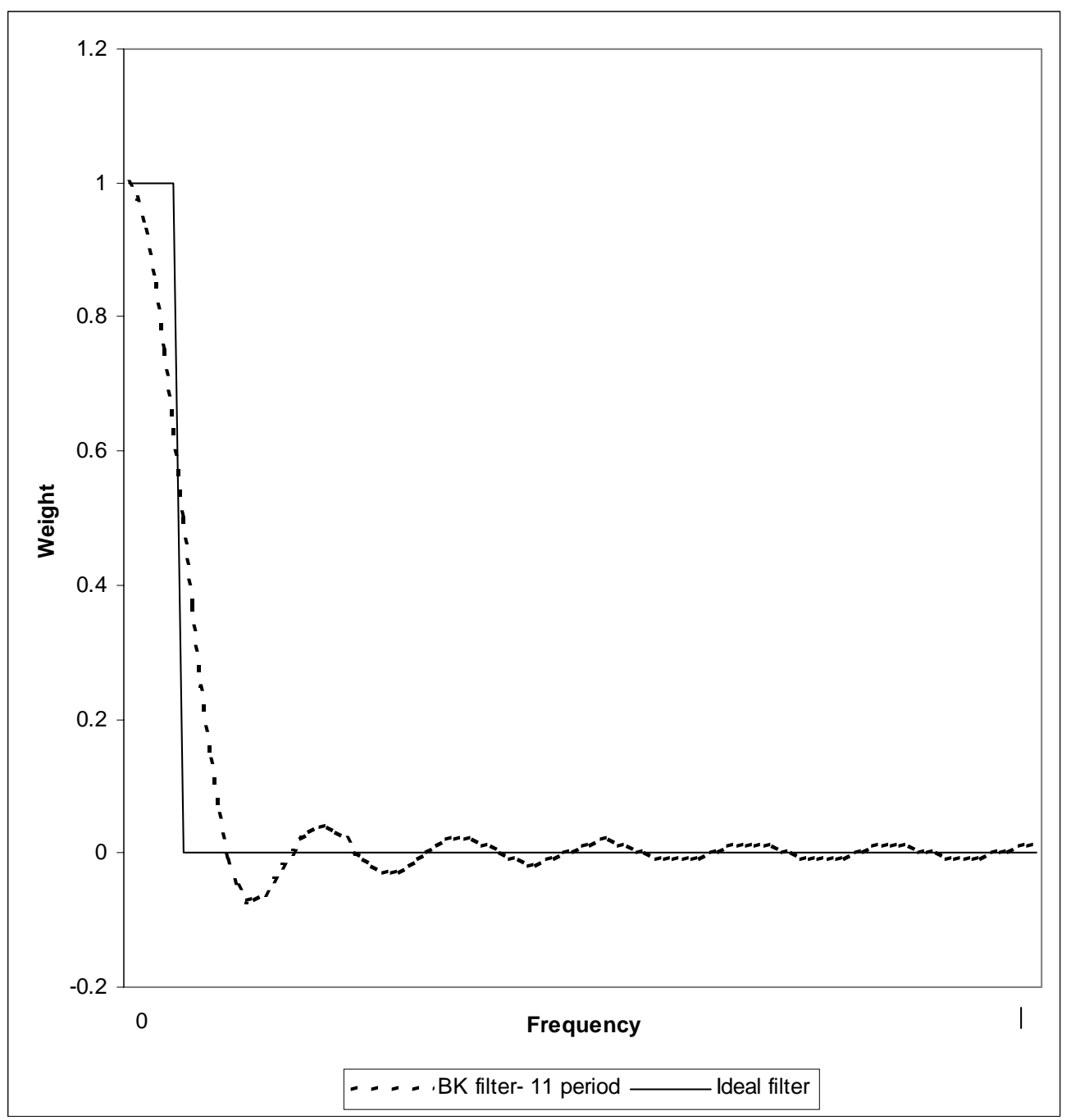


Figure 8. Sample Job Flows

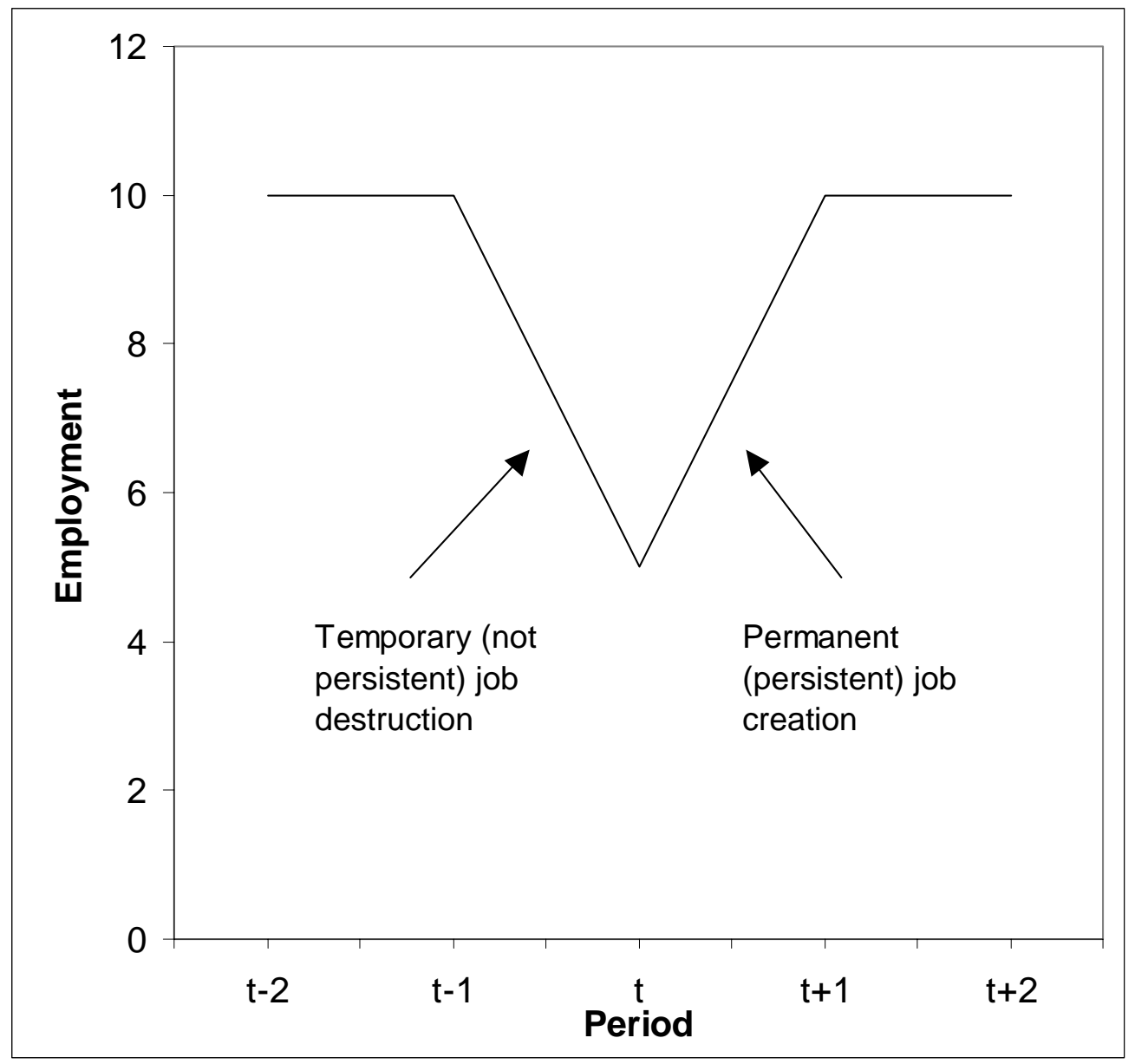


Figure 9. Persistent Job Flows

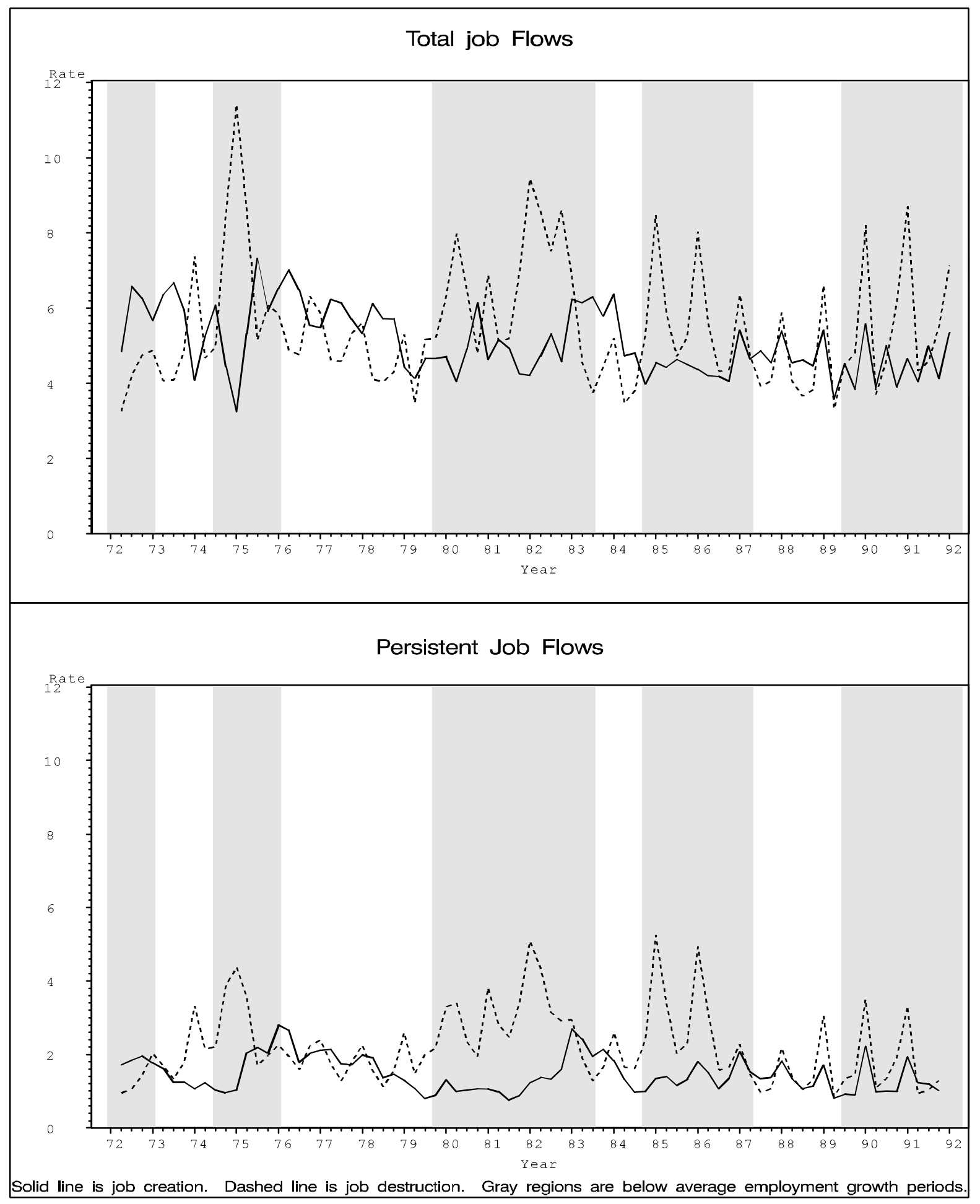


Figure 10. Cross Sectoral Job Flows

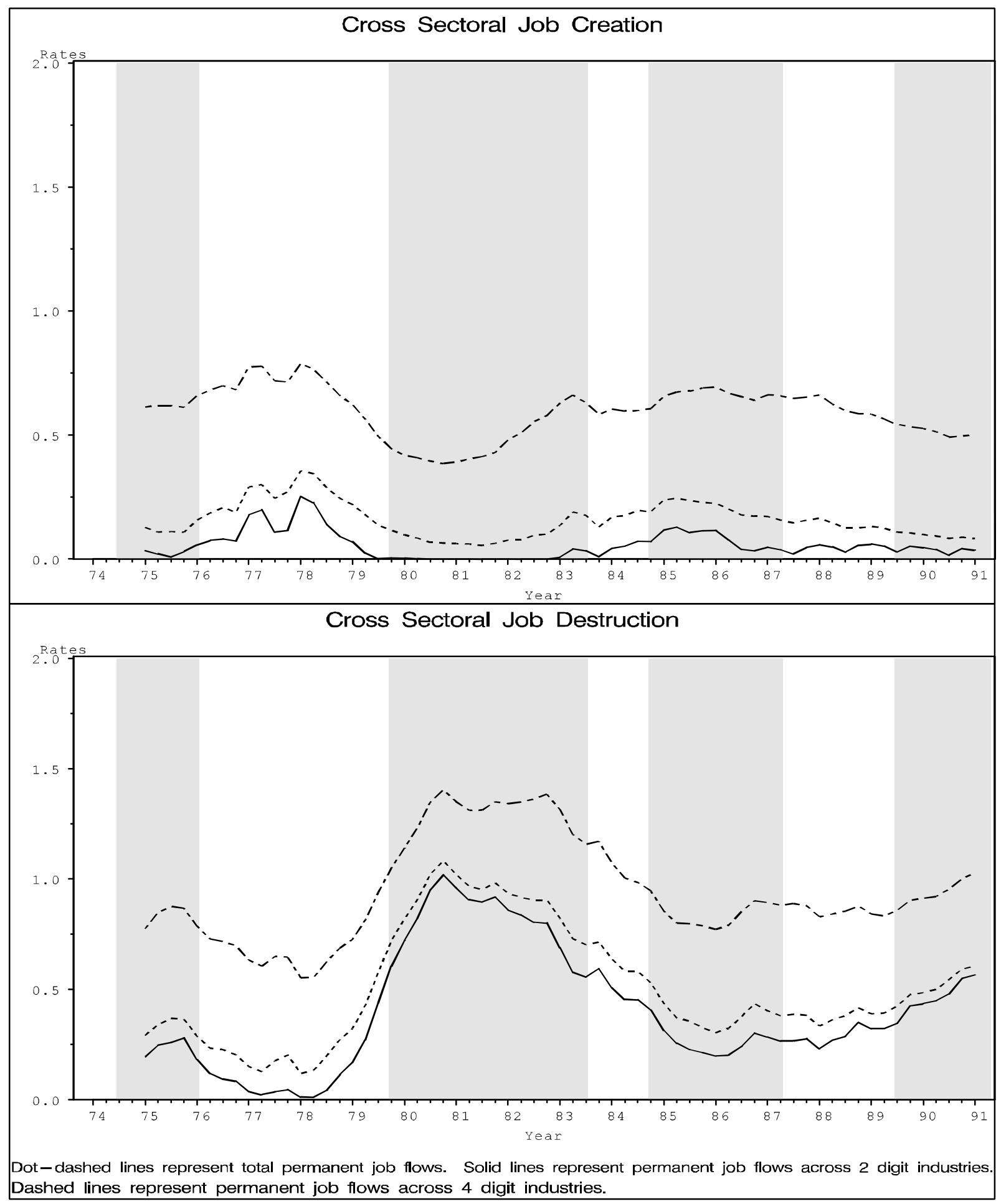

